\title{
Primary Tumors of the Spine
}

\author{
Sebnem Orguc, $\mathrm{MD}^{1}$ Remide Arkun, $\mathrm{MD}^{1}$ \\ 1 Department of Radiology, Celal Bayar University, Manisa, Türkiye \\ ${ }^{2}$ Department of Radiology, Ege University, İzmir, Türkiye \\ Semin Musculoskelet Radiol 2014;18:280-299.
}

Address for correspondence Sebnem Orguc, MD, Department of
Radiology, Celal Bayar University, Manisa, Türkiye
(e-mail: sebnemorguc@superonline.com; sebnemorguc@hotmail.com).

\begin{abstract}
Spinal tumors consist of a large spectrum of various histologic entities. Multiple spinal lesions frequently represent known metastatic disease or lymphoproliferative disease. In solitary lesions primary neoplasms of the spine should be considered. Primary spinal tumors may arise from the spinal cord, the surrounding leptomeninges, or the extradural soft tissues and bony structures. A wide variety of benign neoplasms can involve the spine including enostosis, osteoid osteoma, osteoblastoma, aneurysmal bone cyst, giant cell tumor, and osteochondroma. Common malignant primary neoplasms are chordoma, chondrosarcoma, Ewing sarcoma or primitive neuroectodermal

Keywords

- spinal tumor

- extradural tumor

- magnetic resonance imaging

tumor, and osteosarcoma. Although plain radiographs may be useful to characterize some spinal lesions, magnetic resonance imaging is indispensable to determine the extension and the relationship with the spinal canal and nerve roots, and thus determine the plan of management. In this article we review the characteristic imaging features of extradural spinal lesions.
\end{abstract}

Spinal tumors consist of a large spectrum of various histologic entities. Primary spinal tumors may arise from the spinal cord (intraaxial or intramedullary space), the surrounding leptomeninges (intradural extramedullary space), or the extradural soft tissues and bony structures (extradural space). Almost $60 \%$ of the spinal tumors are located in the extradural space, whereas $40 \%$ are located within the dural sac. Primary tumors of the spine are uncommon and represent $<5 \%$ of all bone neoplasms as compared with secondary metastatic disease, multiple myeloma, and lymphoma. ${ }^{1}$

Clinical signs and symptoms of spinal tumors are variable and nonspecific. Most common symptom is pain, which is present in $85 \%$ of patients with primary spinal tumors. ${ }^{2}$ Other symptoms include back pain, weakness, radicular pain, and paresthesia, which may often be attributed to degenerative disease. Together with the relatively low incidence of spinal tumors in comparison with degenerative processes, a delayed diagnosis is quite common.

Imaging features of the primary spinal lesions are often characteristic, and the various available imaging modalities provide useful tools for narrowing the differential diagnosis and for planning further clinical treatment (-Table 1).

Issue Theme Spine; Guest Editor, Mara Epermane, MD

\section{Benign Tumors of the Osseous Spine}

\section{Enostosis}

Enostosis, also called a bone island, is a frequent benign hamartomatous osseous spinal lesion with a developmental origin. ${ }^{3}$ It is frequently located between $\mathrm{T} 1$ and $\mathrm{T} 7$ in the thoracic spine and between $\mathrm{L} 2$ and $\mathrm{L} 3$ in the lumbar spine. It is composed of cortical bone with irregular margins merging with the medullary bone, commonly adjacent to the endosteal surface. The spiculated or thornlike lesions are typically round or oval with a size up to $2 \mathrm{~cm}$ in diameter. On magnetic resonance imaging (MRI) enostoses demonstrate low signal on both T1-weighted images and T2-weighted images parallel to cortical bone. The surrounding trabecular bone displays normal signal (-Fig. 1). Intraosseous vacuum phenomena may mimic a focus of enostosis with low signal on all sequences; however, it usually exhibits well-defined margins (-Fig. 2). These features allow differentiation of these lesions from other sclerotic spine lesions including osteoblastic metastases, osteoid osteoma, and low-grade osteosarcoma in the vast majority of cases, avoid unnecessary evaluation, and obviate the need for biopsy. However, biopsy may be considered if there is an increase in size. Enostosis is a
Copyright @ 2014 by Thieme Medical Publishers, Inc., 333 Seventh Avenue, New York, NY 10001, USA. Tel: +1(212) 584-4662.
DOI http://dx.doi.org/ 10.1055/s-0034-1375570. ISSN 1089-7860. 


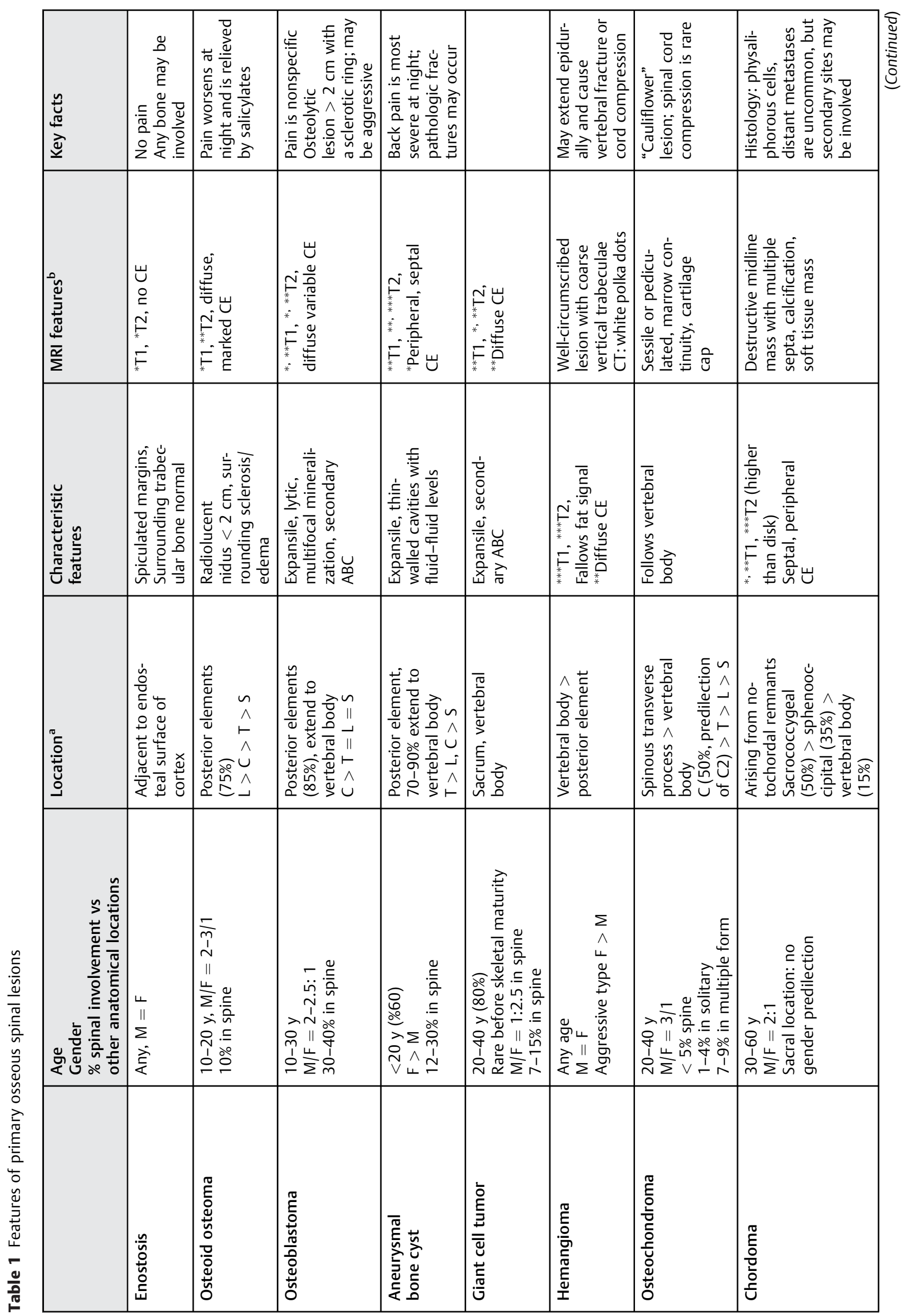




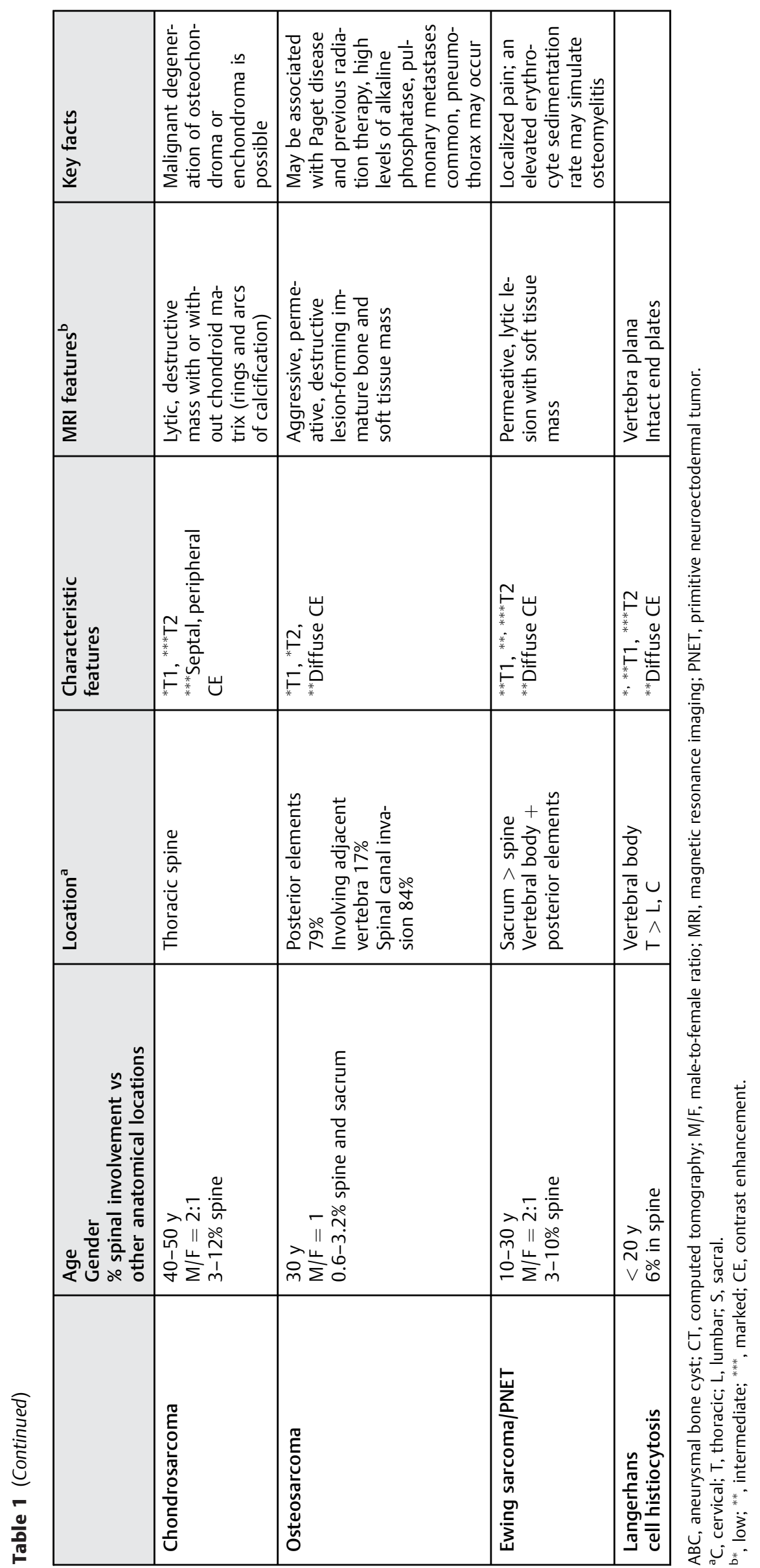



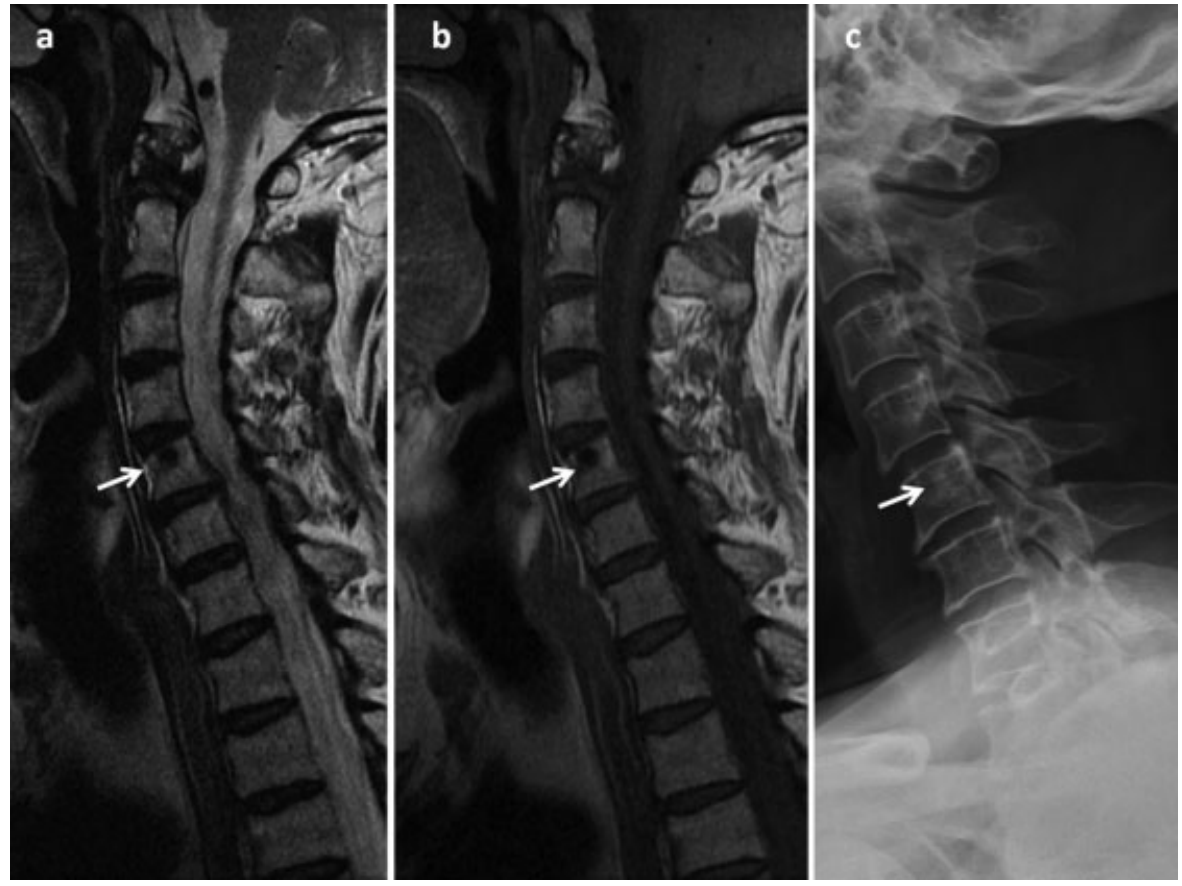

Fig. 1 A sclerotic bone island in the upper half of the corpus of the C5 vertebra (arrows). (a) T2-weighted sagittal, (b) T1-weighted sagittal images show a small lesion with low signal intensity, (c) lateral X-ray. The focus of enostosis with irregular margins has high density similar to cortical bone.

typically solitary lesion; however, multiple lesions are related to osteopoikilosis, osteopathia striata, and melorheostosis.

\section{Osteoid Osteoma}

Osteoid osteoma is a benign bone tumor that occurs most frequently in young patients, 7 to 25 years of age, with a slight male predominance. Most patients experience pain that worsens at night and is relieved by nonsteroidal anti-inflammatory drugs. ${ }^{4,5}$ The pain may also be aggravated by the imbibing alcohol.

Osteoid osteomas are small (by definition $<2.0 \mathrm{~cm}$ in diameter) vascular lesions with well-organized

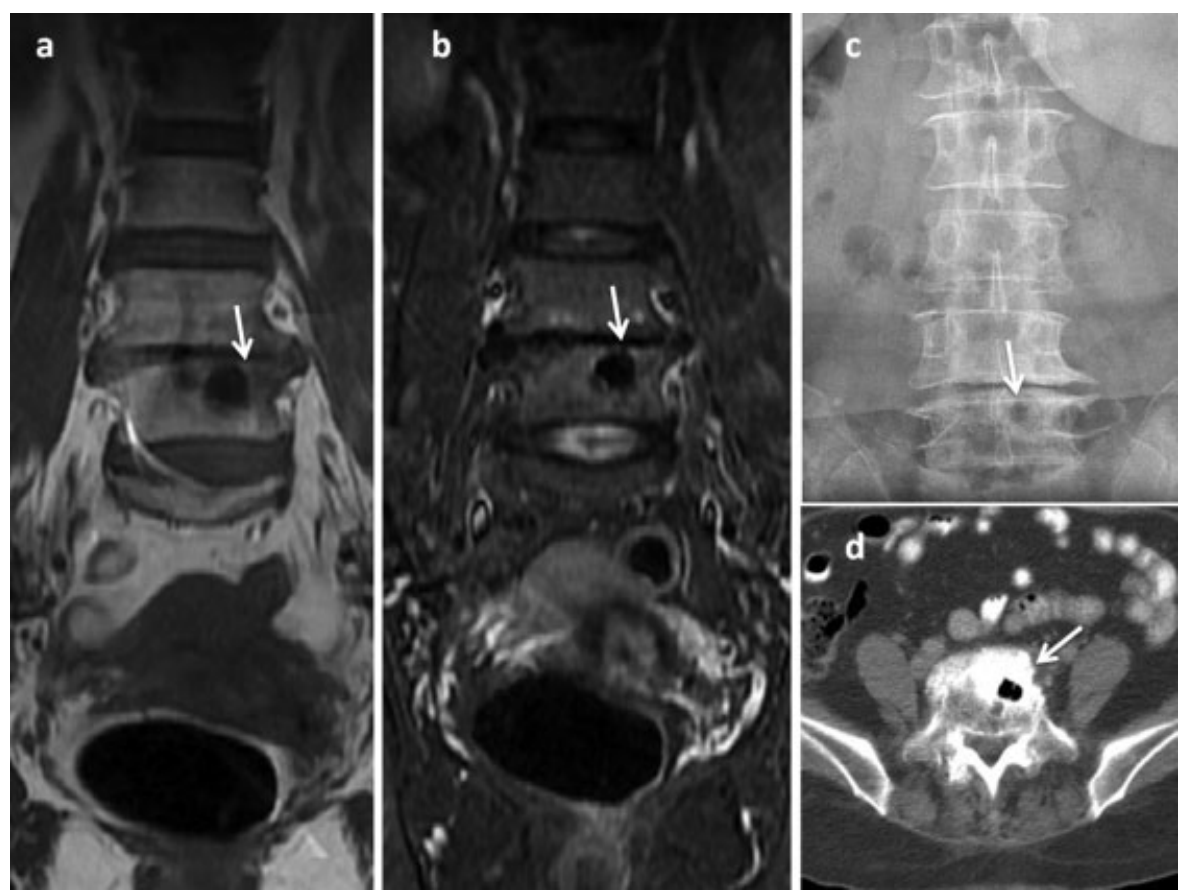

Fig. 2 A 60-year-old female patient with intraosseous vacuum in the upper plate and body of the L5 vertebrae mimicking an enostosis on magnetic resonance imaging (arrows). (a) T1-weighted coronal, (b) short tau inversion recovery coronal images demonstrate a well-defined focus with low signal. (c) Anteroposterior lumbar X-ray and (d) axial computed tomography image show the intraosseous air density with surrounding sclerosis, related to adjacent degenerative disk disease. 

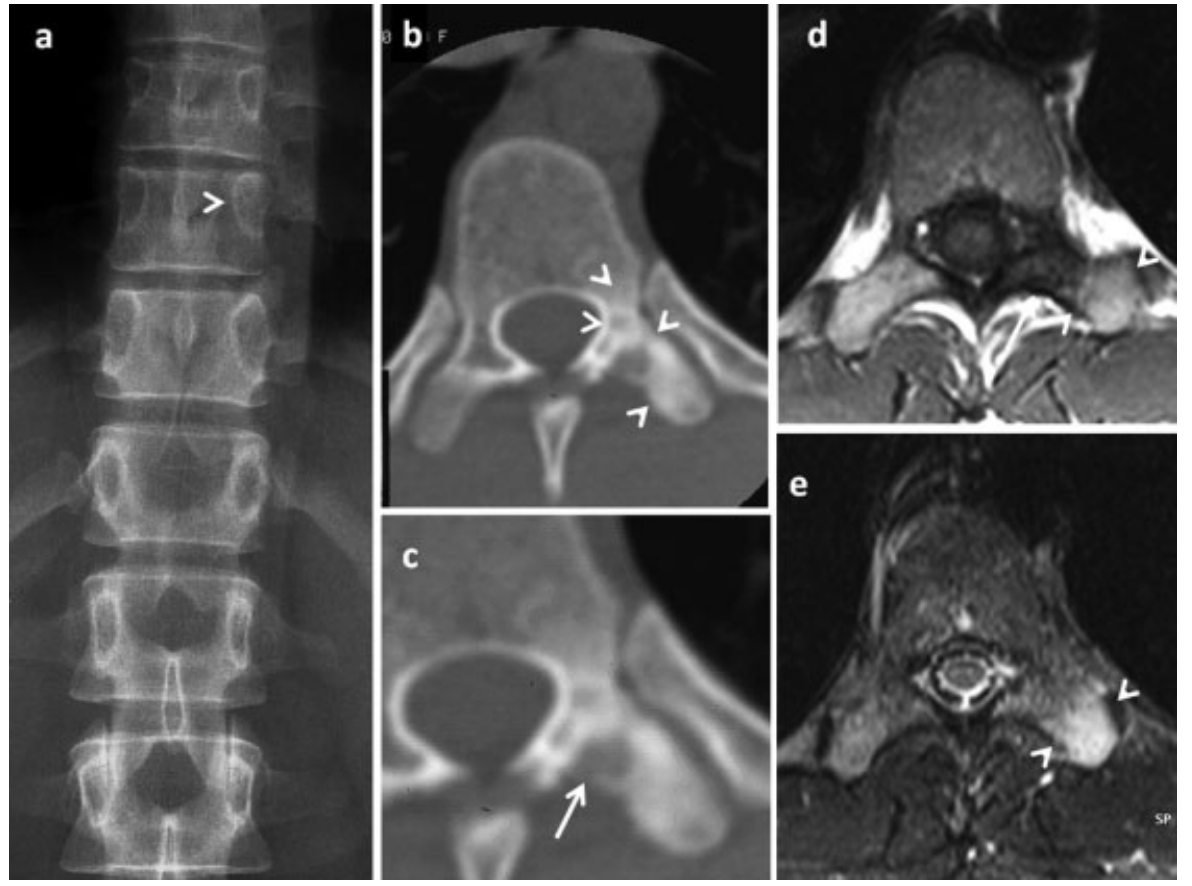

Fig. 3 Osteoid osteoma of the posterior elements of the D10 vertebra in an adolescent boy with back pain worsening at nights. (a) Anteroposterior dorsolumbar X-ray shows very subtle sclerosis of the left peduncle of the D10 vertebra in comparison with the right side, which is almost undetectable (small arrowhead). (b, c) Axial computed tomography scan demonstrating the small radiolucent nidus (arrow) at the base of the left transverse process as well as the surrounding sclerosis at the peduncle, lamina, and transverse process (arrowheads). (d) T1-weighed axial and (e) T2-weighted axial magnetic resonance images showing edema pattern of the left transverse process (arrowheads).

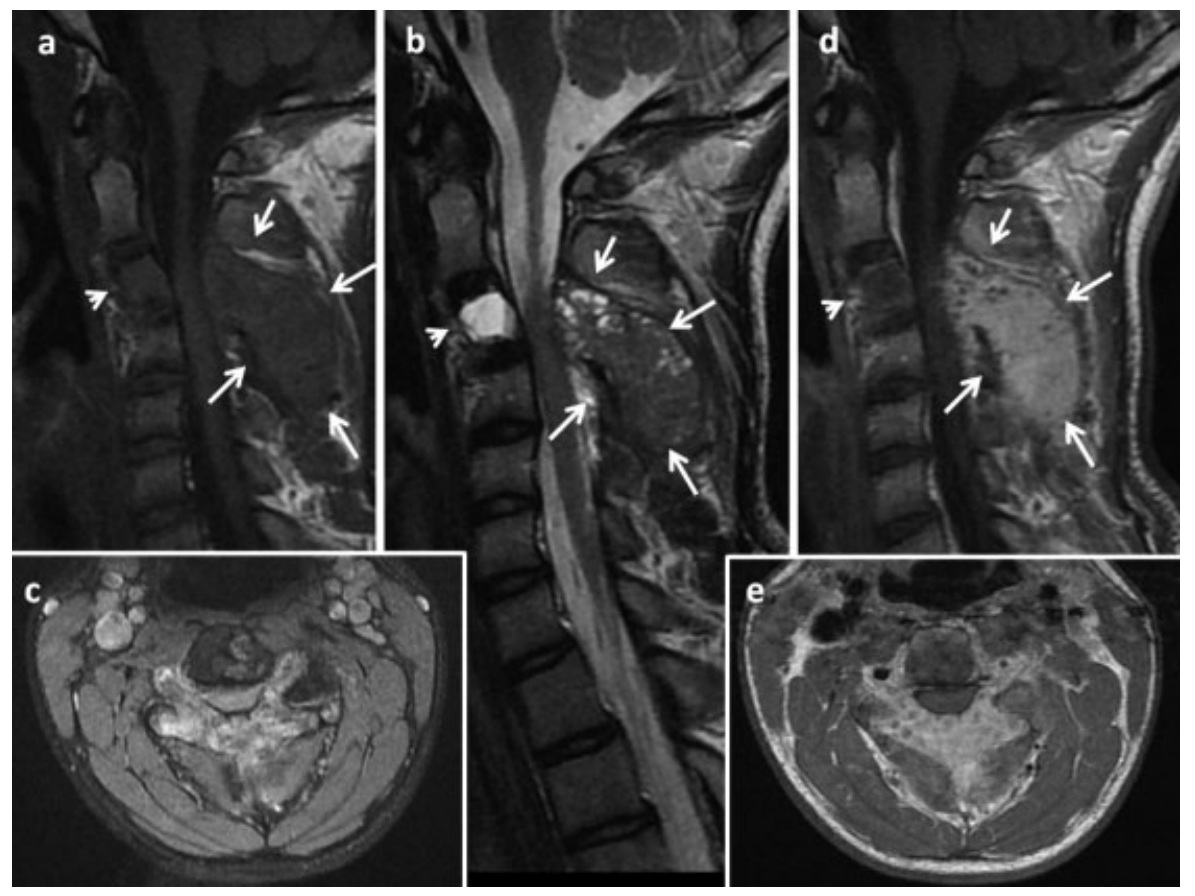

Fig. 4 A 16-year-old male patient with chondroblastoma. (a) Sagittal T1-weighted, (b) sagittal T2-weighted, (c) axial gradient recalled echo T2*, (d) sagittal postcontrast T1-weighed, (e) axial postcontrast T1-weighted magnetic resonance images. A mass lesion of the C3 vertebra compressing on the cervical spinal cord with a cystic component at the body (arrowheads) and a markedly enhancing mostly solid part involving the posterior elements (arrows). 
interconnected trabecular bone in a background of fibrous connective tissue. These lesions are frequently surrounded by a variable degree of reactive bone and are often associated with cortical thickening and bony sclerosis.

The lumbar spine is the most frequently affected portion of the spine (59\% of lesions) followed by the cervical (27\%), thoracic (12\%), and sacral segments (2\%). Spinal osteoid osteomas are located within the posterior elements of the vertebra (pedicles, superior and inferior articular processes, lamina, transverse, and spinous processes) in $93 \%$ of cases. The remaining lesions are located within the vertebral body. ${ }^{6,7}$

Osteoid osteomas are often difficult to detect on radiographs owing to their small size, radiolucent appearance, and posterior element location. Computerized tomography (CT) demonstrates a radiolucent nidus with or without intranidal calcification and surrounding cortical thickening and sclerosis with great success ( - Fig. 3). More than $50 \%$ of nidi are partially calcified, $\sim 20 \%$ are completely calcified, and 30\% show no calcifications. However, some of these tumors may display misleading imaging findings, making it difficult to differentiate these tumors from other diseases. The central mineralization has a sequestrum-like appearance and may mimic osteomyelitis, osteoblastic metastases, lymphoma, Langerhans cell histiocytosis (LCH), osteoblastoma, and malignant fibrous histiocytoma. A vascular groove sign is a moderately sensitive and highly specific sign for distinguishing osteoid osteoma from other radiolucent bone lesions on $\mathrm{CT}^{8}$

The nidus has low to intermediate signal on T1-weighted images and intermediate to high signal on T2-weighted images on MRI. Surrounding reactive edema, both in the marrow and soft tissues, can be extensive, may obscure visualization of the nidus, and potentially suggest a more aggressive lesion. The soft tissue edema and delay of diagnosis can lead to muscle atrophy in the chronic period. Although MRI has been reported to be of limited value, dynamic contrast-enhanced MRI was found to show the nidus more clearly in osteoma osteoid than nonenhanced MRI. Most osteoid osteomas show arterial phase enhancement and rapid partial washout as a result of hypervascularity of the nidus. $^{9-11}$

Radiofrequency ablation is the preferred method for appendicular lesions and has been used in the spine with some caution. Laser and alcohol ablation are also accepted methods that may increase in use in the future. ${ }^{12,13}$ Surgical excision is also curative if the nidus is completely removed.

\section{Osteoblastoma}

Osteoblastomas usually present in young adults between the second and third decades of life. Men are affected twice as commonly as women. It is a rare benign osteoid-producing tumor also called giant osteoid osteoma and osteogenic fibroma. Osteoblastomas commonly affect the vertebral column (30-40\% of cases) and most frequently originate from the posterior elements ( $85 \%$ of lesions) with $42 \%$ extending into the vertebral body. They may present with pain, paresthesias, paraparesis, or even paraplegia. ${ }^{14}$

Osteoblastoma and osteoid osteoma are variants of the same benign process and histologically indistinguishable from each other. Only the size is used as a differential criterion in which a lesion with a nidus $>2 \mathrm{~cm}$ is classified as osteoblastoma. The natural history of osteoblastomas is slow growth as opposed to the relative stability of osteoid
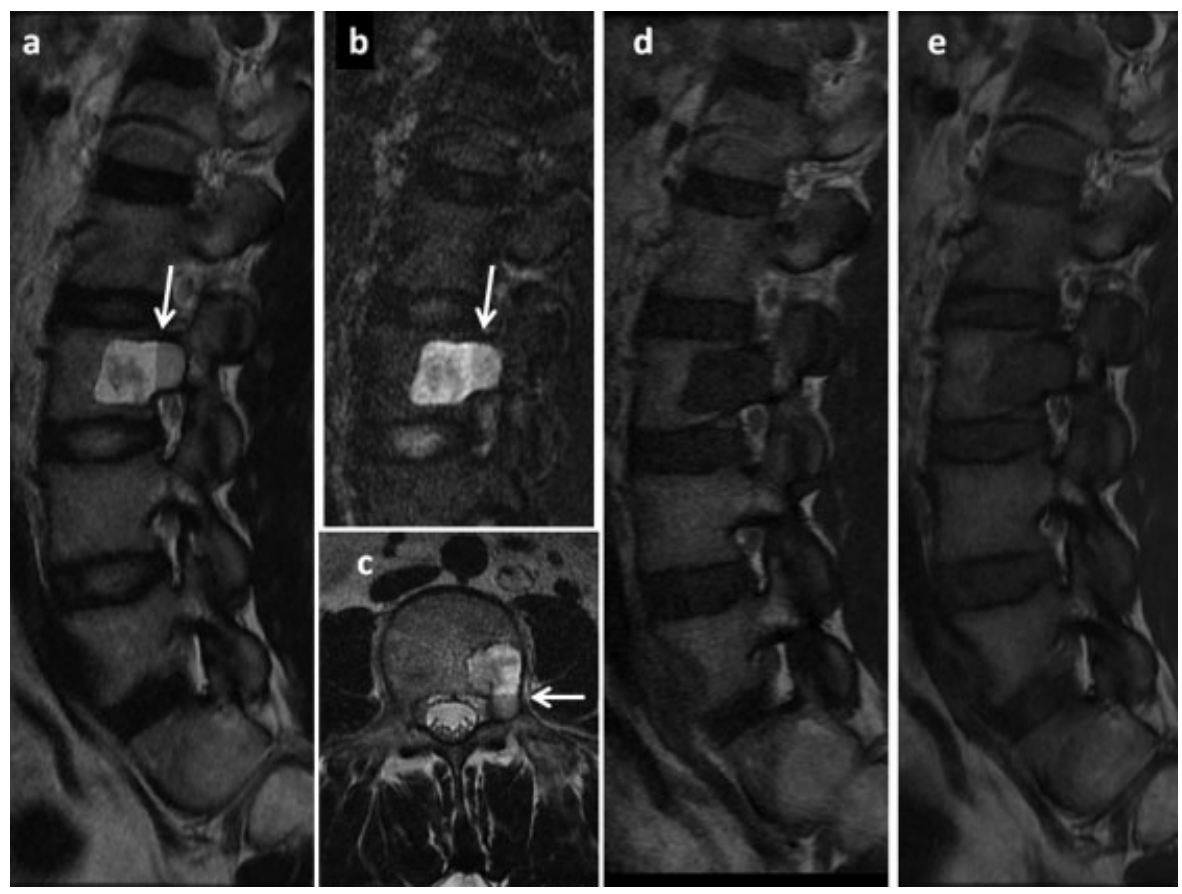

Fig. 5 Aneurysmal bone cyst at the body and left peduncle of the L3 vertebra. (a) Sagittal T2-weighted, (b) sagittal short tau inversion recovery, (c) axial fast spin-echo T2-weighted, (d) Sagittal T1-weighted, (e) postcontrast T1-weighted magnetic resonance images demonstrate a welldefined, slightly expansile mass lesion with fluid-fluid levels (arrows) and minimal contrast enhancement. 
osteomas. Malignant transformation to osteosarcoma is rare. Osteoblastomas are more aggressive than osteoid osteomas, with a higher recurrence rate: 10 to $15 \%$ for the less aggressive and $>50 \%$ for the more aggressive lesions.

Spinal osteoblastomas may present with variable radiologic appearances. First pattern is similar to osteoid osteomas and composed of a radiolucent nidus and surrounding sclerosis, but they are $>2 \mathrm{~cm}$ in diameter. The most common appearance of spinal osteoblastoma is an expansile lesion with a prominent sclerotic rim and multiple small calcifications. The more aggressive type demonstrates an expansile pattern with matrix calcifications, bone destruction, and paravertebral extension mimicking an aneurysmal bone cyst or bone metastasis (-Fig. 4). Furthermore, aneurysmal bone cyst components are present in 10 to $15 \%$ of cases. $^{15}$

The diagnostic examination of choice is CT; however, MRI depicts the surrounding soft tissue involvement to a better
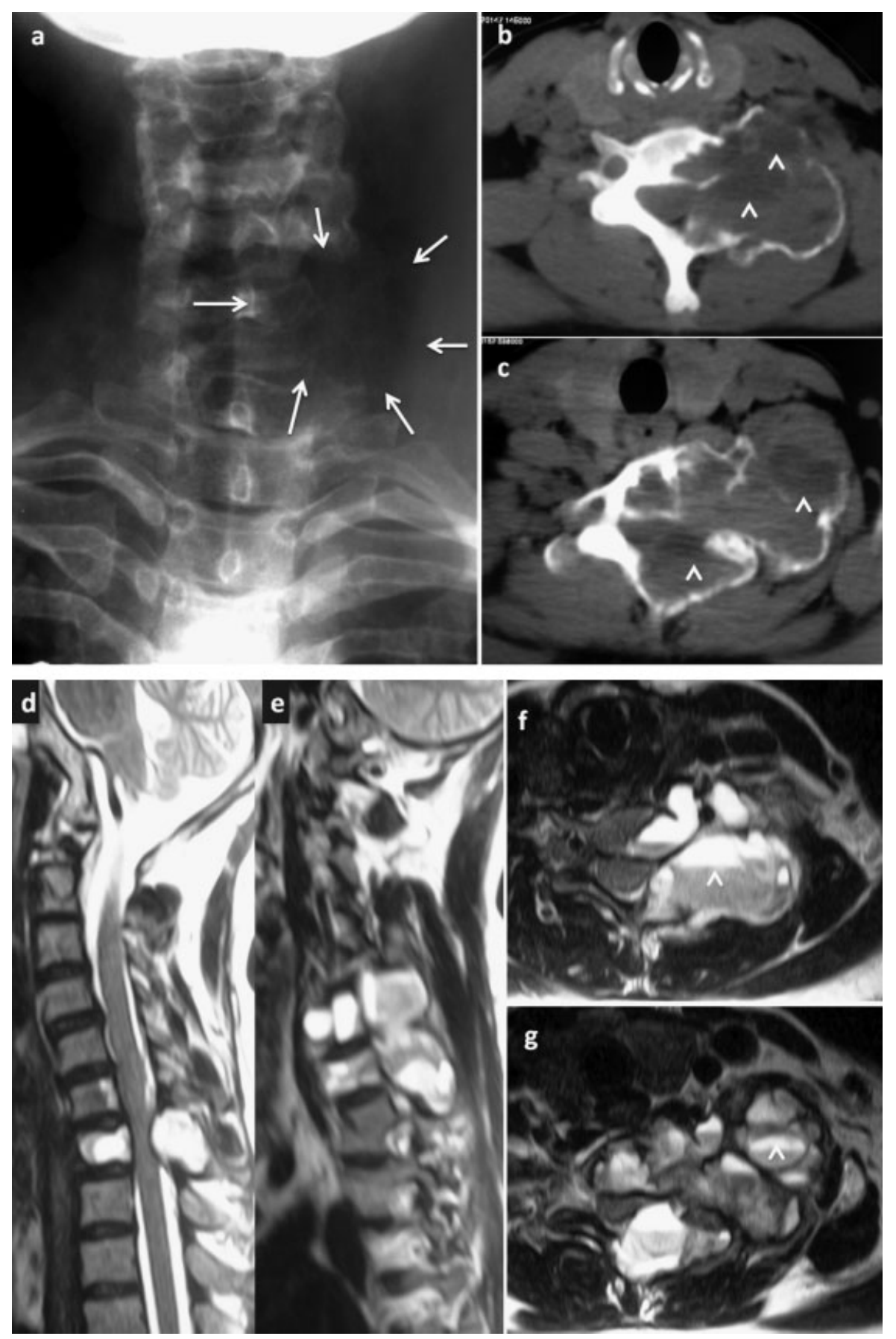

Fig. 6 A 47-year-old female patient with neck pain with pathologic diagnosis of aneurysmal bone cyst. (a) Anteroposterior X-ray lytic destructive lesion at the left side of C6-C7 vertebra (arrows). (b, c) Fluid-fluid levels (arrowheads) demonstrated in the multilocular expansile lesion involving both the body and posterior elements on consecutive computed tomography images. Magnetic resonance imaging of the same patient. (d, e) Sagittal and (f, $\mathbf{g}$ ) axial T2-weighted images demonstrate multiple fluid-fluid levels representing hemorrhagic elements at various ages (arrowheads). 

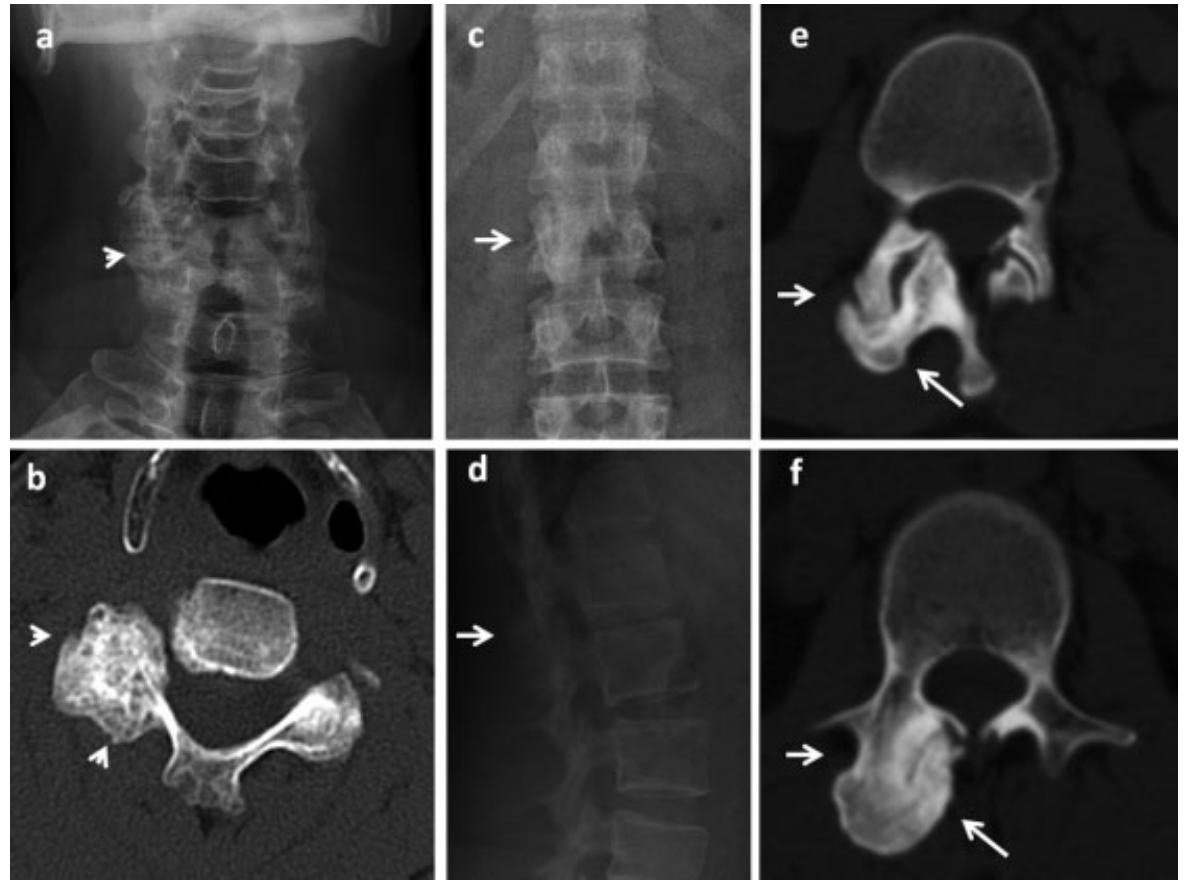

Fig. 7 Two different patients with osteochondromas of the spine. First patient: A 45-year-old man with a osteochondroma originating from the right C5-C6 facet joint. (a) Anteroposterior (AP) cervical X-ray, (b) axial computed tomography (CT) scan demonstrates a well-defined boneforming tumor with lobulated contours (arrowheads). Second patient: A 36-year-old woman with back pain. (c, d) AP and lateral X-rays, (e, f) axial CT scan shows similar imaging findings at the right superior articular process of L2 vertebra (arrows).
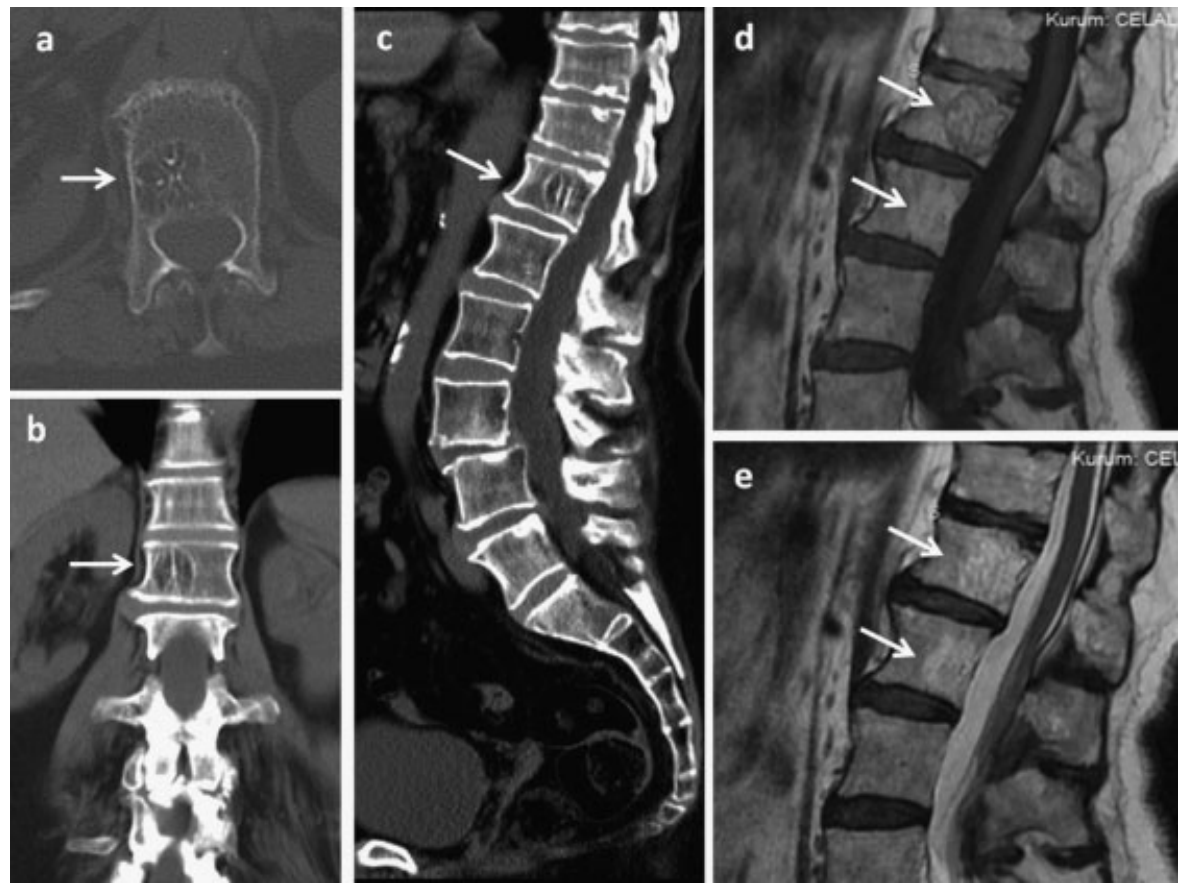

Fig. 8 (a) Axial computed tomography (CT) scan image showing multiple punctate areas of sclerosis creating the white polka-dot sign. (b) Coronal and (c) sagittal reconstructed CT images displaying prominent vertical trabecula of corpus of the D12 vertebra resembling a honeycomb and forming the "corduroy" sign. (d) Sagittal T1-weighted and (e) sagittal T2-weighted magnetic resonance images demonstrating two hemangiomas at the D12 and L1 vertebrae with high signal intensity (arrows). 
extent. CT shows the nidus, the multifocal (as opposed to central in osteoid osteomas) matrix calcification, the sclerotic margin, the expansile bone remodeling, or a thin osseous shell around its margins.

Surgical resection is the treatment of choice with a recurrence rate of 10 to $15 \%$ for conventional osteoblastomas. ${ }^{14,16}$ Rarely, aggressive osteoblastoma may undergo malignant transformation to osteosarcoma and metastasize.

\section{Aneurysmal Bone Cyst}

Aneurysmal bone cyst (ABC) typically affects patients $<20$ years of age, with a mild female predilection. Overall, 12 to $30 \%$ of $A B C s$ are located in spine. Thoracic spine is the most frequently affected segment; lumbar and cervical involvement is less common. Although very rare, sacral $A B C$ is centered in upper segments, similar to giant cell tumor (GCT). Spinal ABCs typically show marked expansile remodeling (-Fig. 5). Although centered in the posterior elements, 75 to $90 \%$ of cases extent into the vertebral body (-Fig. 6). ${ }^{17}$

$\mathrm{CT}$ and MRI of a primary $\mathrm{ABC}$ show single or, more commonly, multiple fluid levels representing hemorrhage with sedimentation. ${ }^{18}$ During cross-sectional imaging, supine positioning for $\sim 10$ minutes may be necessary to detect fluid levels. MRI is also indispensable in determining the extent of the lesion and the relationship to the central canal and nerve roots, like in all spinal tumors. Methemoglobin within the fluid components show increased signal in both T1-weighted and T2- weighted MR images (-Fig. 5). A low signal intensity rim on all pulse sequences corresponds to an intact and often thickened periosteal membrane. Thin rim- and-septal pattern of enhancement is detected after contrast administration. The identification of fluid levels should initiate a search for a solid component that enhances diffusely indicative of a primary lesion (usually GCT or osteoblastoma) with secondary ABC.

The imaging findings closely resemble the histologic appearance of this tumor. Primary ABCs have a characteristic appearance consisting of multiloculated blood-filled spaces. These blood-filled spaces are not lined by endothelium and thus do not represent vascular channels and are separated by thin septa. The septa interposed between the blood-filled spaces are composed of fibrous tissue, giant cells, and reactive bone. $^{19}$

The main surgical therapy for ABCs is curettage and bone grafting. The overall recurrence rate for these lesions is 20 to $30 \%$ and may increase with incomplete resection. ${ }^{20}$

\section{Giant Cell Tumor}

Although commonly thought of as an appendicular lesion, 7 to $15 \%$ of GCTs can present in the spine. Of the tumors located in the spine, the peak incidence is from the second to third decades. These tumors are rare before skeletal maturity and usually present in the second to fourth decade of life. The male-to-female ratio is $1: 2.5$. The sacrum is the most commonly affected spinal location, followed by the thoracic, cervical, and lumbar segments in descending order. ${ }^{21,22}$ GCTs may increase rapidly in size during pregnancy, presumably due to hormonal stimulation.

GCT is a lytic, expansile lesion composed of osteoclastlike giant cells, with no evidence of matrix mineralization.

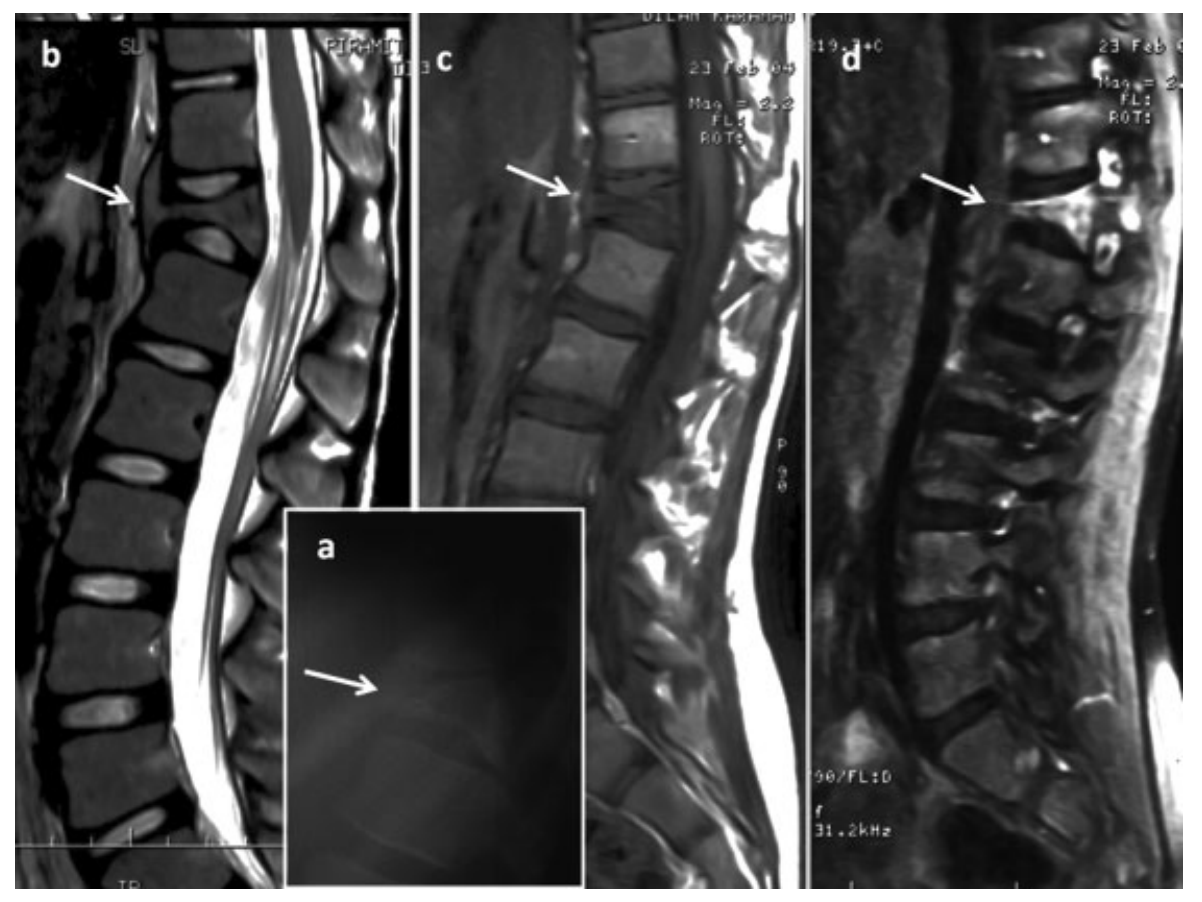

Fig. 9 A 22-year-old woman with Langerhans cell histiocytosis. (a) Lateral X-ray of the dorsolumbar spine demonstrating vertebral collapse more prominent on the ventral side with preservation of the end plates. (b) Sagittal T2-weighted magnetic resonance (MR) image demonstrating vertebra plana with slightly high T2 signal and small soft tissue component under the anterior longitudinal ligament. (c) Sagittal T1-weighted MR image shows anterior compression at the D12 vertebral body with low T1 signal. (d) Sagittal postcontrast T1-weighted MR image with fat saturation shows marked enhancement of the pathologic compression fracture (arrows). 


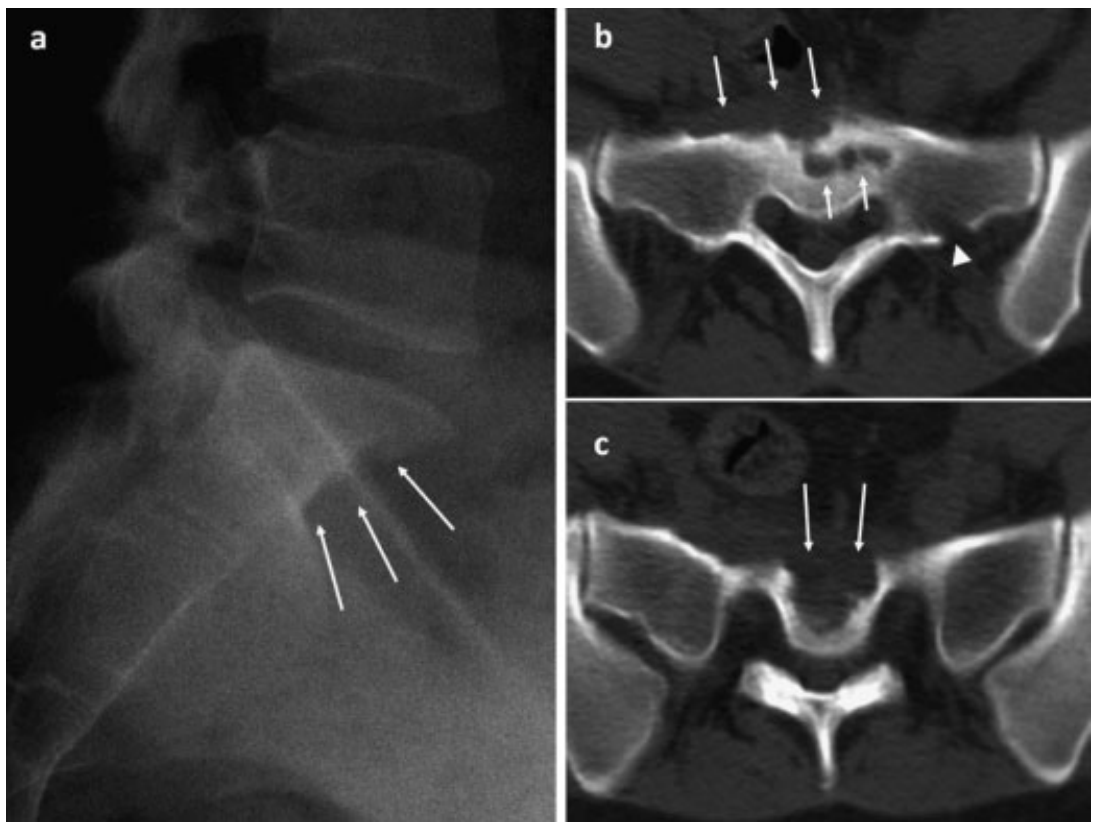

Fig. 10 A 22-year-old patient with Langerhans cell histiocytosis. (a) Lateral lumbosacral X-ray, (b, c) axial computed tomography images display small lytic lesion on the anterior aspect of the S1 vertebra (arrows). A small focus of destruction accompanies at the dorsal side of left sacral wing (arrowhead).

GCT of the sacrum, which is frequently centered in the S1S2 segment, may extend across the sacroiliac joint. ${ }^{23}$ GCT usually affects the vertebral body with extension into the posterior elements and paraspinal soft tissues. Vertebral collapse and involvement of the adjacent intervertebral disks and vertebra may occur. A total of 90 to $95 \%$ of GCTs show low to intermediate signal intensity on the T1-weighted and T2-weighted MR images. ${ }^{24}$ Fluid-fluid levels on cross-sectional imaging representing secondary ABC components should be avoided during biopsy because they do not harbor diagnostic tissue of the primary tumor.
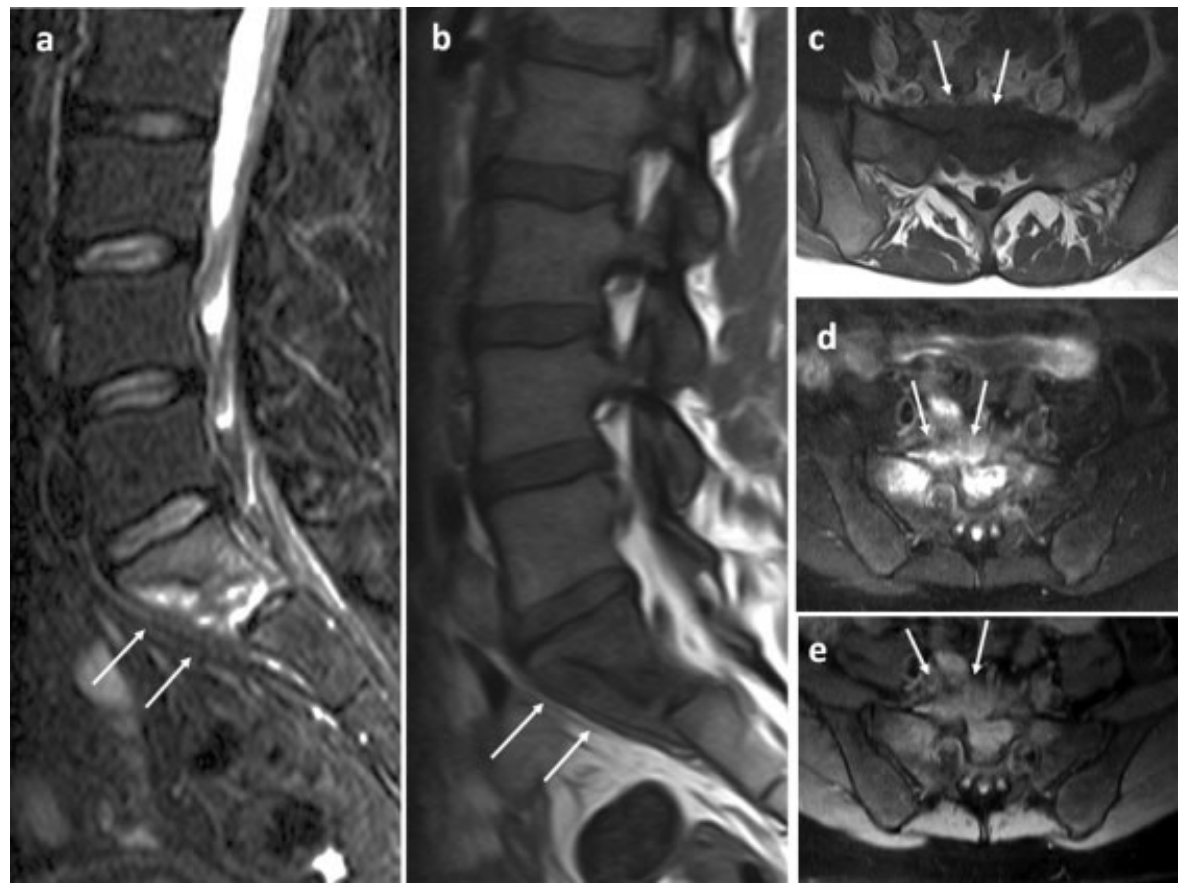

Fig. 11 Magnetic resonance (MR) examination of the same case. (a) Sagittal short tau inversion recovery image. (b) Sagittal T1-weighted, (c) axial T1-weighted MR images, (d) fast spin-echo proton density axial MR image with fat saturation, (e) postcontrast T1-weighted MR image with fat saturation demonstrates pathologic bone marrow signal with a small soft tissue component and cortical destruction (arrows). 


\section{Osteochondroma}

A cartilage-covered osseous excrescence in continuity with parent bone is an osteochondroma. Hereditary multiple exostosis (HME), diaphyseal aclasis, hereditary deforming chondroplasia, multiple osteochondromatosis, multiple cartilaginous exostosis, dyschondroplasia, and Ehrenfried disease are alternative names. ${ }^{25}$ Male-to-female ratio is $3: 1$. It is an uncommon tumor in the spine comprising only 1 to $4 \%$ of solitary exostoses and is usually discovered during the third and fourth decades of life. In cases of HME, they present a decade earlier in 7 to $9 \%$ of patients. Even if they can be located anywhere along the spine, they appear to have a predilection for the cervical spine, particularly $\mathrm{C} 2{ }^{3}$ Because lesions protruding into the spinal canal lead to neurologic symptoms earlier, they are often discovered when they are smaller, in comparison with lesions projecting posteriorly. ${ }^{26}$

Osteochondromas of the spine are often difficult to detect on radiographs because of the complex osseous anatomy and frequent small size of lesions. The continuity of the marrow and cortical portions of the bone from which it originates is pathognomonic and best evaluated with thin-section multiplanar CT images ( - Fig. 7). The hyaline cartilage cap (low to intermediate signal on T1-weighted and high signal intensity on T2-weighted MR images) is usually apparent with MRI. A cartilage cap thicker than $1.5 \mathrm{~cm}$ in adults is suspicious for malignant transformation to a chondrosarcoma. Surgical excision with resection at the point of cortical and marrow junction to the underlying bone is usually curative.

\section{Hemangioma}

Hemangiomas are common, usually incidentally discovered benign developmental lesions. Reported incidence in autopsy series is $11 \%$ of spines, and multifocal lesions are present in 25 to $30 \%$ of cases. ${ }^{27}$ Lesions occur most frequently in the thoracic spine but may be present at any spinal level. ${ }^{28}$ Hemangiomas reveal prominent vertical trabeculae on radiographs resembling a "honeycomb" and classically called the "corduroy sign." They form the appearance of multiple punctate areas of sclerosis on axial CT images, creating the "white polka-dot" sign. Fatty stroma and serpentine vascular channels are responsible for the low density components on plain radiographs and CT images. The fat overgrowth exhibits signal parallel to subcutaneous adipose tissue, and the vascular components demonstrate high signal intensity in a serpentine pattern on T2-weighted MR imaging reflecting slow blood flow. The polka-dot or corduroy appearance may also be seen, respectively, on axial and sagittal/coronal MR images as low signal intensity regions (-Fig. 8).

Histologically, hemangiomas represent a collection of thin-walled endothelial-lined blood vessels interspersed between nonvascular components, such as fat, muscle, fibrous tissue, or bone. Multiple types (capillary, cavernous, arteriovenous, and venous) have been described, with the capillary type the most common. ${ }^{29}$

Hemangiomas with extension into the posterior elements, with paraspinal involvement and without a large amount of intertrabecular fatty stroma, are more likely to be associated with symptoms. Lesions containing less fat and more vascular stroma tend to be less common, and they are located between T3 and T9. Large hemangiomas that weaken the vertebral bodies can result in fractures. Pathologic fracture or epidural extension may show a characteristic "curtain sign." A vertebral body lesion extending posteriorly to the anterior epidural space displaces the posterior longitudinal ligament. However,
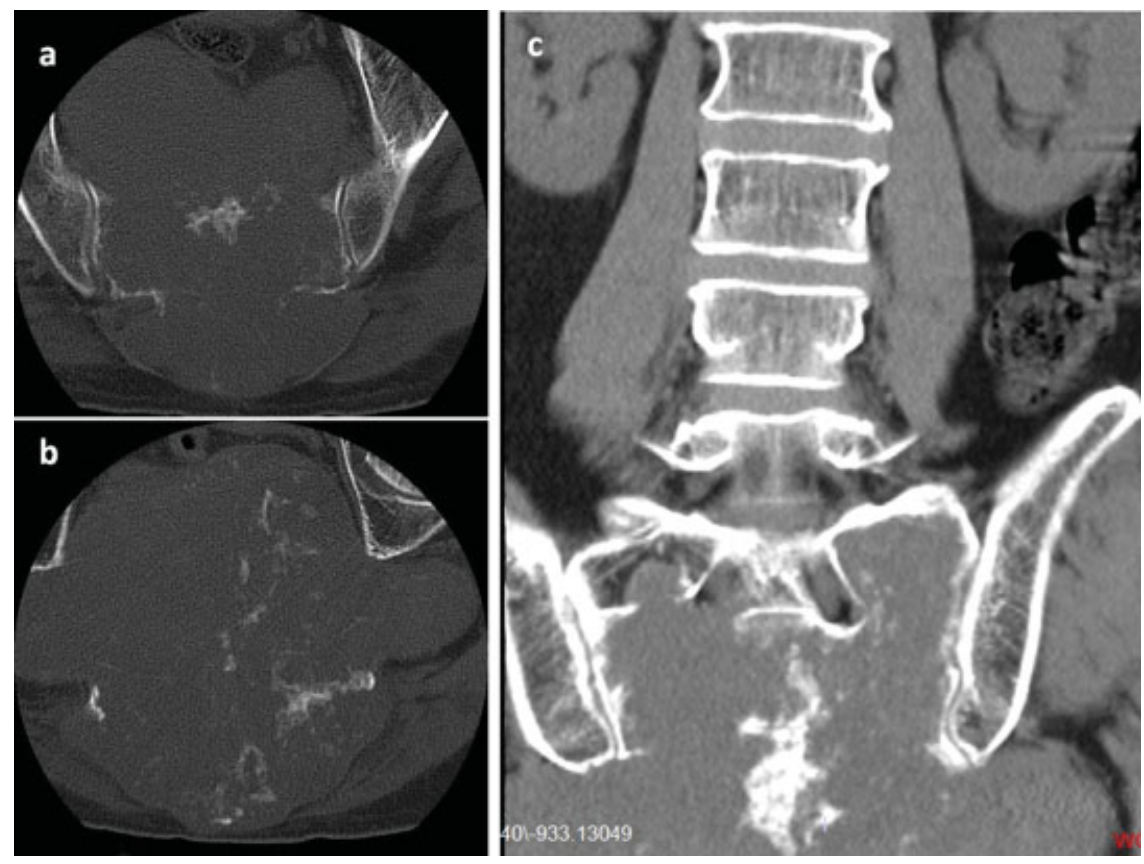

Fig. 12 A 59-year-old man with sacral chordoma. (a, b) Axial computed tomography scan and (c) coronal reconstructed images show lytic destructive sacral mass lesion with intratumoral calcification. 
this displacement is limited by the strong medial fixation, giving a bilobular aspect to the epidural mass in the axial images, which is commonly called "curtain sign." Current treatment options for symptomatic vertebral hemangiomas include endovascular embolization, vertebrectomy, sclerotherapy, and vertebroplasty. ${ }^{30}$

\section{Langerhans Cell Histiocytosis}

Langerhans cell histiocytosis ( $\mathrm{LCH}$ ) is a benign lesion that can affect the spine in $6 \%$ of cases. The thoracic segments are more commonly affected than the lumbar and cervical regions. ${ }^{31}$

Radiologically, LCH demonstrates focal lytic lesions that may progress to uniform vertebral collapse forming the classic appearance of "vertebra plana," which is seen in only $\sim 15 \%$ of cases. The end plates are typically preserved. Partial vertebral collapse and focal marrow replacement may also occur.

The MRI appearance of $\mathrm{LCH}$ reveals areas of low signal marrow replacement on T1-weighted and high signal intensity on T2-weighted MR images (-Fig. 9). Findings may be very subtle on plain films (-Fig. 10). MR imaging may also depict the soft tissue component ( - Fig. 11). Small areas of soft tissue extension and surrounding hematoma secondary to vertebral collapse may be detected. MR imaging is useful in discriminating active disease from chronic changes, which are seen as vertebral body deformity without abnormal signal intensity. LCH can be self-limiting if involvement is restricted to bone and may not require active treatment, ${ }^{31}$ but close observation is necessary to exclude progression of disease. Therapeutic options include low-dose radiotherapy, steroid injections, chemotherapy, and surgical curettage. ${ }^{32}$

\section{Malignant Tumors of the Osseous Spine}

\section{Chordoma}

A chordoma is a malignant tumor arising from the embryonic remnants of the notochord that extend from Rathke pouch to the coccyx. Histologic identification of physaliphorous ("bubble bearing" vacuolated) cells confirms the diagnosis. It is the most common nonlymphoproliferative primary malignant neoplasm of the spine in adults.

It commonly presents in middle-age patients and has a peak incidence in the fifth decade and rarely detected before 30 years of age. Chordomas are almost exclusively seen in the midline. Approximately $50 \%$ of chordomas are localized to the sacrum and 35\% localized to the clivus. Unlike GCT, which prefers the upper sacral segments, sacral chordomas are most frequently centered in the lower sacrum (S3-S4). The remaining $15 \%$ of chordomas affect the mobile spinal segments, particularly the cervical region. It is very rare for chordomas to arise in a paracentral location, which is along the spine in the soft tissues and in this case they are called "parachordoma."33,34

Bone destruction predominates in spinal chordomas, although lesions affecting the mobile portions of the spine may show sclerosis. A total of $64 \%$ of sacrococcygeal lesions show intratumoral calcification ${ }^{35}$ ( - Fig. 12). Chordomas originating in the spine almost invariably extend into the paraspinal soft tissues, and the sacroiliac joint is crossed in $23 \%$ of cases. $^{33}$ Chordomas show signal characteristics parallel to nucleus pulposus of the disk (notochord) in MR imaging, that is low-intermediate signal on T1-weighted and very high signal on T2-weighted MR images (-Fig. 13). However,

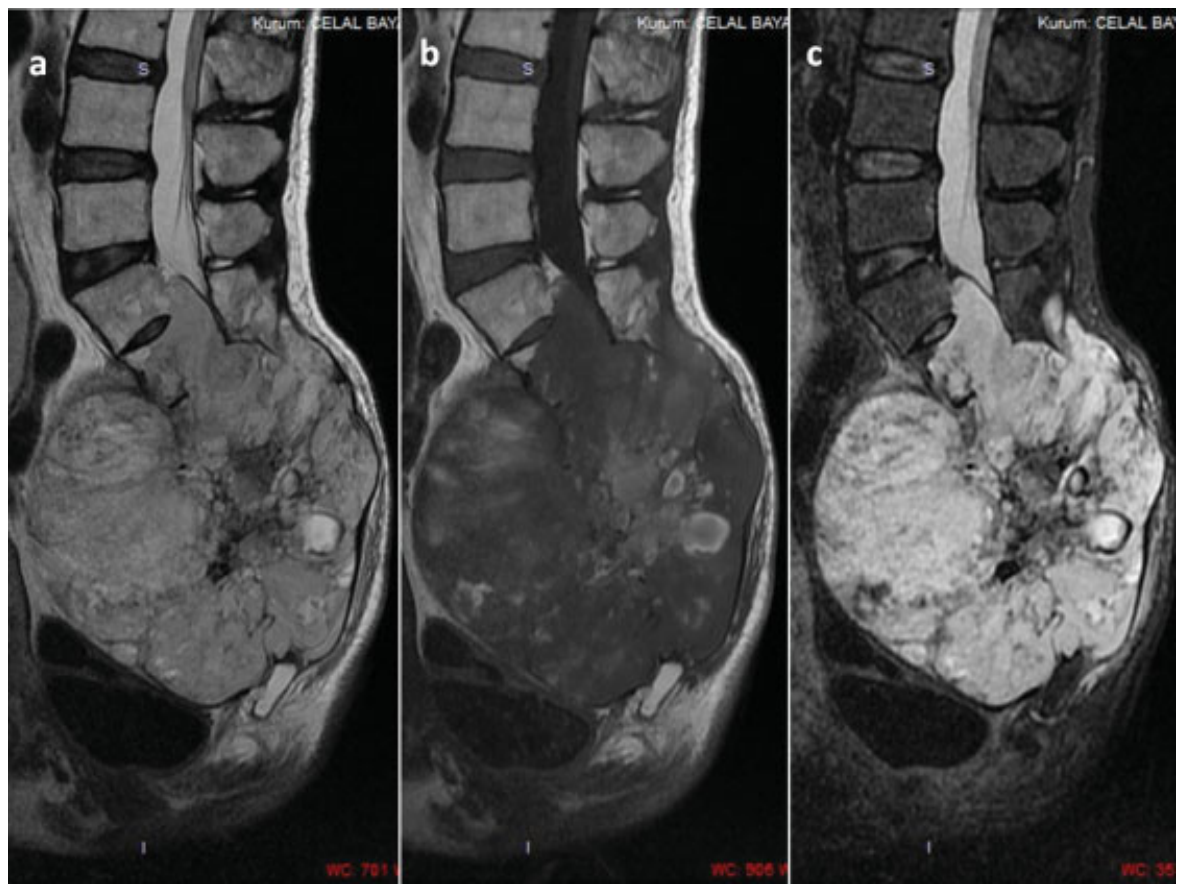

Fig. 13 Magnetic resonance (MR) examination of the same patient with sacral chordoma. (a) Sagittal T2-weighted, (b) sagittal T1-weighted, (c) sagittal short tau inversion recovery MR images. Lobulated mass lesion with heterogeneous signal characteristics originating from the lower sacral segments has a large soft tissue component extending into the pelvis, epidural space, posterior elements, and paravertebral muscles. 

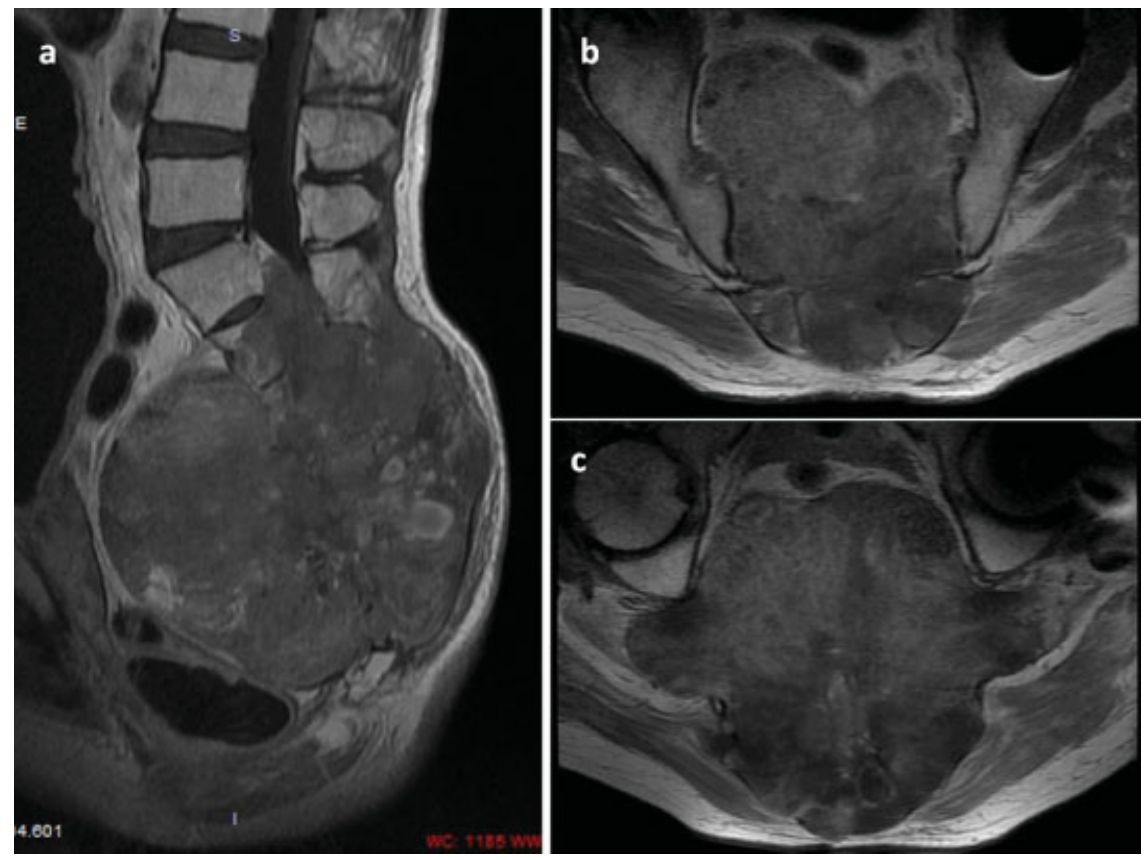

Fig. 14 Postcontrast (a) sagittal and (b, c) axial T1-weighted magnetic resonance images of the same patient show mild enhancement of the mass lesion, abutting but not crossing the sacroiliac joints.

spheno-occipital and intracranial chordomas may display high signal on T1-weighted images due to high protein content. ${ }^{34}$ Contrast enhancement is usually in a thick peripheral and septal pattern similar but more prominent than chondrosarcoma (-Fig. 14). The location and thus resectability of the lesion usually determines the patient's prognosis. Local recurrence is common; distant metastases are rarer.

\section{Chondrosarcoma}

A malignant tumor of connective tissue, chondrosarcoma is characterized by formation of chondroid matrix by tumor cells. It is the second most common nonlymphoproliferative primary malignant tumor of the spine in adults. The spine represents the primary site in 3 to $12 \%$ of chondrosarcomas. ${ }^{36}$ The male-to-female ratio is $2-4: 1$, and the mean age of presentation is 45 years. Although chondrosarcomas can be located at any level, the thoracic segments of the spine are the more commonly affected (-Fig. 15).

These tumors can present as primary chondrosarcomas or as malignant transformation of osteochondromas or enchondromas. Most spinal chondrosarcomas are histologically lowgrade lesions. They may be centered in the vertebral body or posterior elements with destruction of the osseous structures and frequent involvement of the posterior elements (40\%). Mineralized chondroid matrix with typical ring-and-arc-nodules pattern is best appreciated on radiographs or CT image (-Fig. 16). ${ }^{36}$ On MR imaging the nonmineralized lobular areas of hyaline cartilage growth typically demonstrates low signal intensity on T1-weighted images and high signal intensity on T2-weighted images (-Fig. 17) and frequently reveal a peripheral and septal enhancement pattern on postcontrast images (-Fig. 18).
Treatment for spinal chondrosarcoma is surgical resection when possible. Incomplete resection frequently leads to recurrence and eventual patient demise in $74 \%$ of cases. ${ }^{36}$

\section{Osteosarcoma}

An osteosarcoma is a malignant tumor containing immature matrix and osteoid produced directly by the neoplastic cells. It is also called an osteogenic sarcoma. Overall, 0.6 to $3.2 \%$ of osteosarcomas occur in the spine. Spinal localization has a peak incidence in the fourth decade, which is higher than the appendicular osteosarcomas; the age range is 8 to 80 years. ${ }^{36-38}$

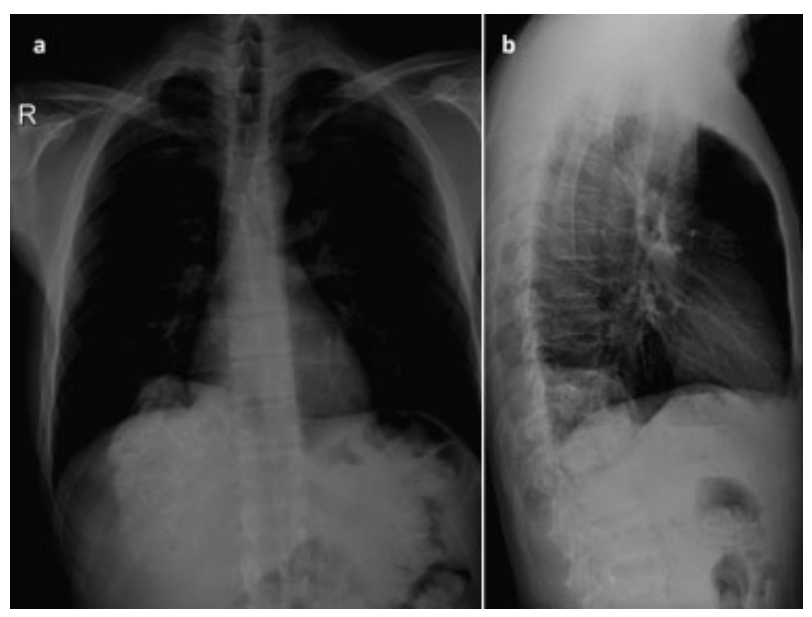

Fig. 15 A 47-year-old man. (a) Posteroanterior and (b) lateral chest Xray demonstrating right paravertebral mass lesion with curvilinear calcifications at the lower thoracic level. 

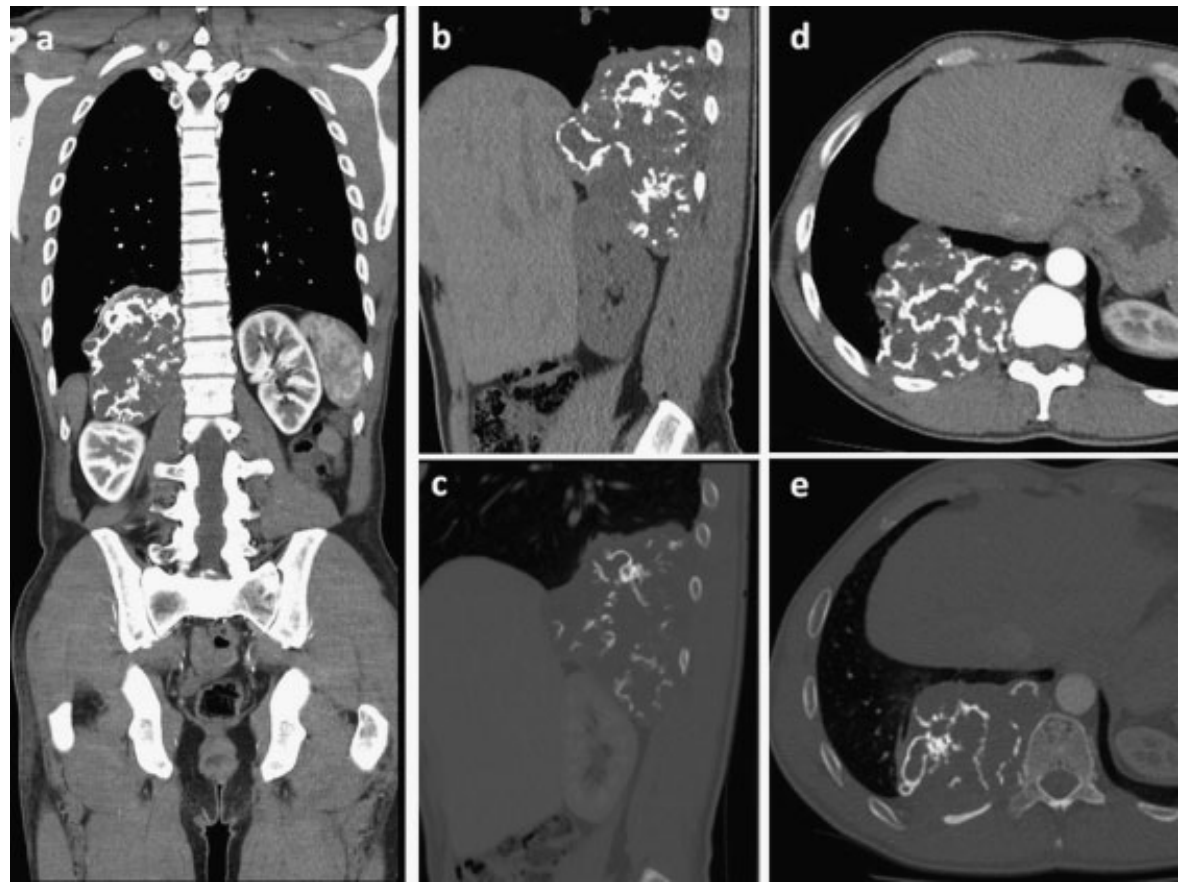

Fig. 16 Computed tomography (CT) examination of the same patient. (a) Coronal, (b, c) sagittal reformatted, (d, e) axial CT images demonstrates the calcified right paravertebral mass lesion displacing the liver and right kidney. The adjacent posterior rib is sclerotic.

There is a male predilection. The patients present with pain, palpable mass, neurologic symptoms, and high serum alkaline phosphatase levels. Pulmonary, bone, and liver metastases are common. Osteosarcoma may be associated with Paget disease and previous radiation therapy. It may also present as a second tumor $\sim 10$ years after detection of retinoblastoma. ${ }^{39}$

Although they have been reported at all levels of the spine, a predilection for the thoracolumbar segments is present. Spinal osteosarcomas tend to be high-grade lesions that are
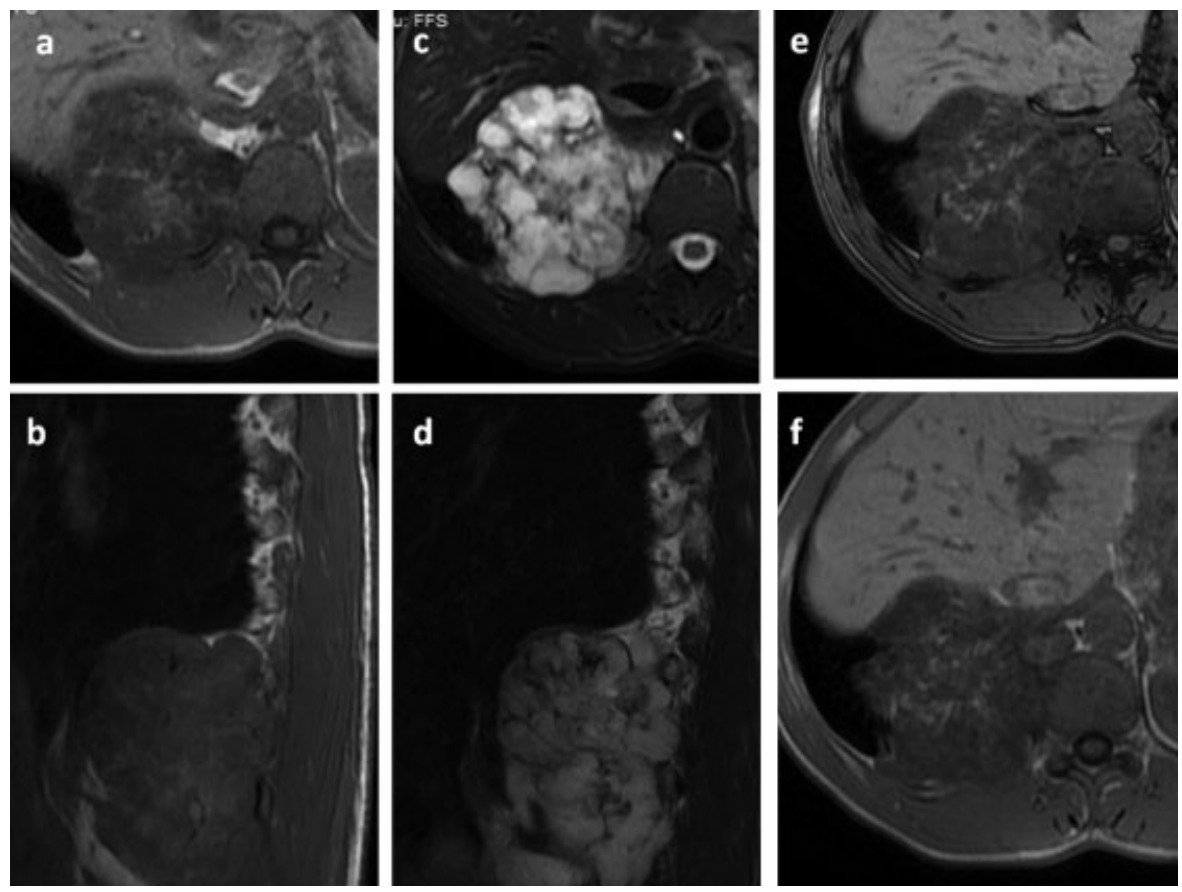

Fig. 17 Magnetic resonance (MR) imaging of the same patient. (a) Axial and (b) sagittal T1-weighted, (c) axial fast spin-echo T2-weighted with fat saturation, (d) sagittal short tau inversion recovery, $(\mathrm{e}, \mathrm{f})$ axial in-phase and out-of-phase MR images of the right paravertebral mass lesion displaying a chondroid matrix with low T1 and high T2 signal intensity. 


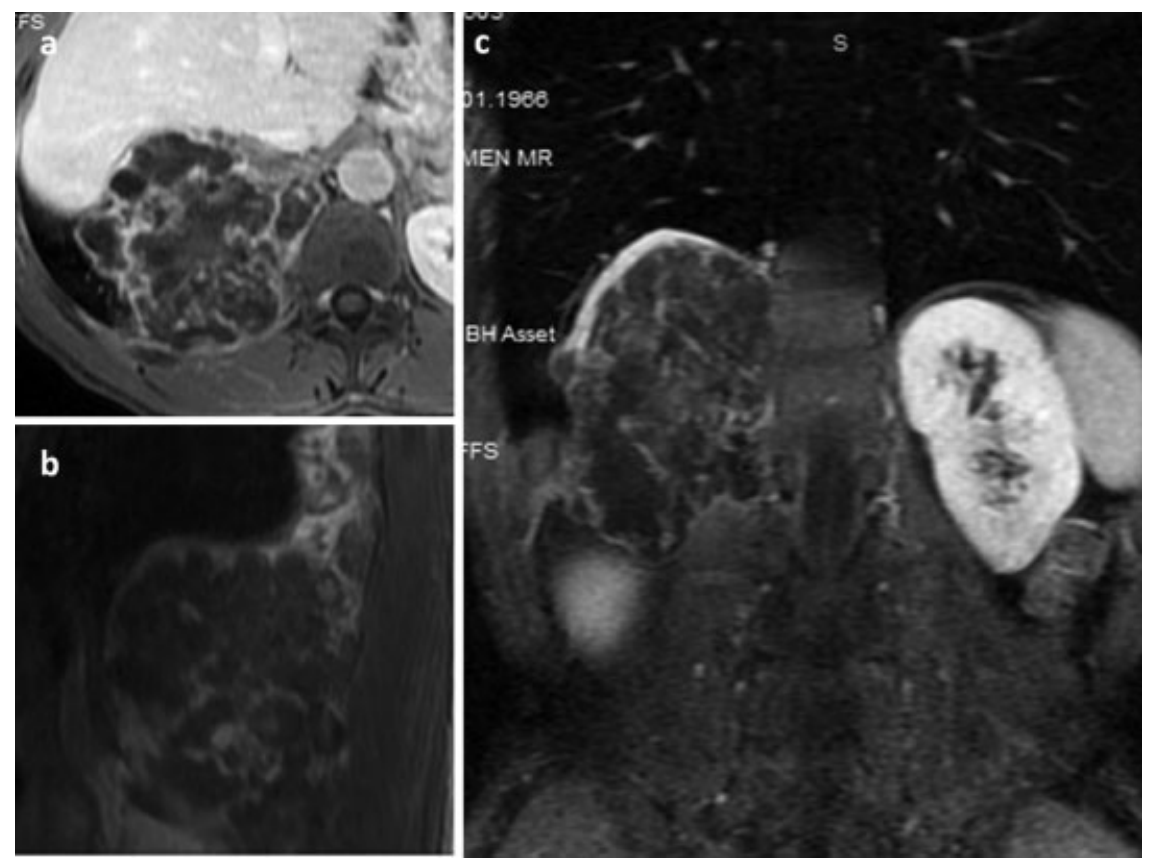

Fig. 18 Magnetic resonance (MR) imaging of the same patient. (a) Axial, (b) sagittal, (c) coronal postcontrast T1-weighted MR images with fat saturation showing septal and peripheral enhancement of the mass lesion.

predominantly osteosclerotic. The heterogeneous mass with ossified and nonossified components is commonly associated with necrosis displaying a mixed osteosclerotic-osteolytic appearance on conventional radiographs and CT images (-Fig. 19). An ivory vertebral body may be recognized with loss of vertebral height, permeative or moth-eaten pattern of bone destruction, cortical interruption, a wide zone of transition, and accompanying soft tissue mass. MRI is useful for evaluating extension of the lesion, particularly the soft tissue component and involvement of the surrounding nerve roots and spinal canal. Mineralized component of the tumor shows low signal in T1-weighted and T2-weighted MR images; the
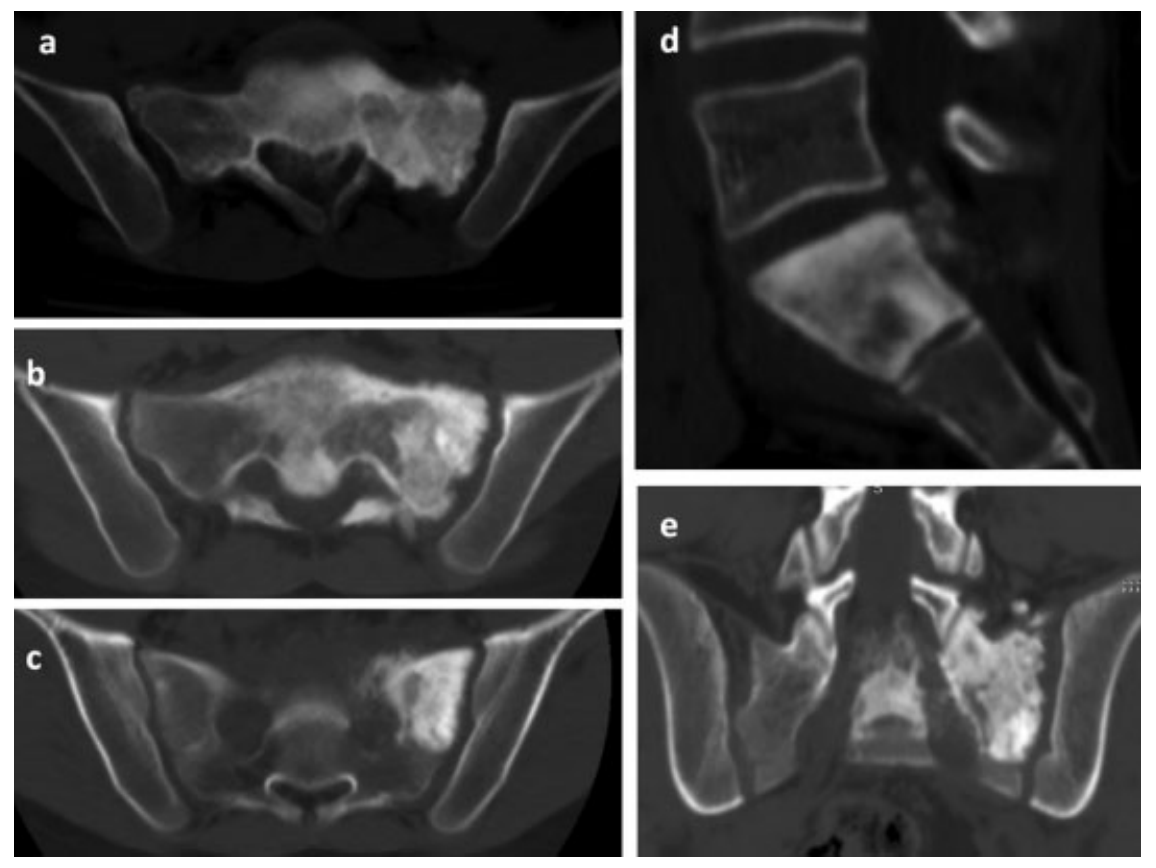

Fig. 19 (a-c) Axial computed tomography scans. (d) Sagittal, (e) coronal maximum-intensity projection reformatted images of a 19-year-old teenager demonstrating a bone-forming tumor infiltrating the corpus and left wing of the sacrum. 


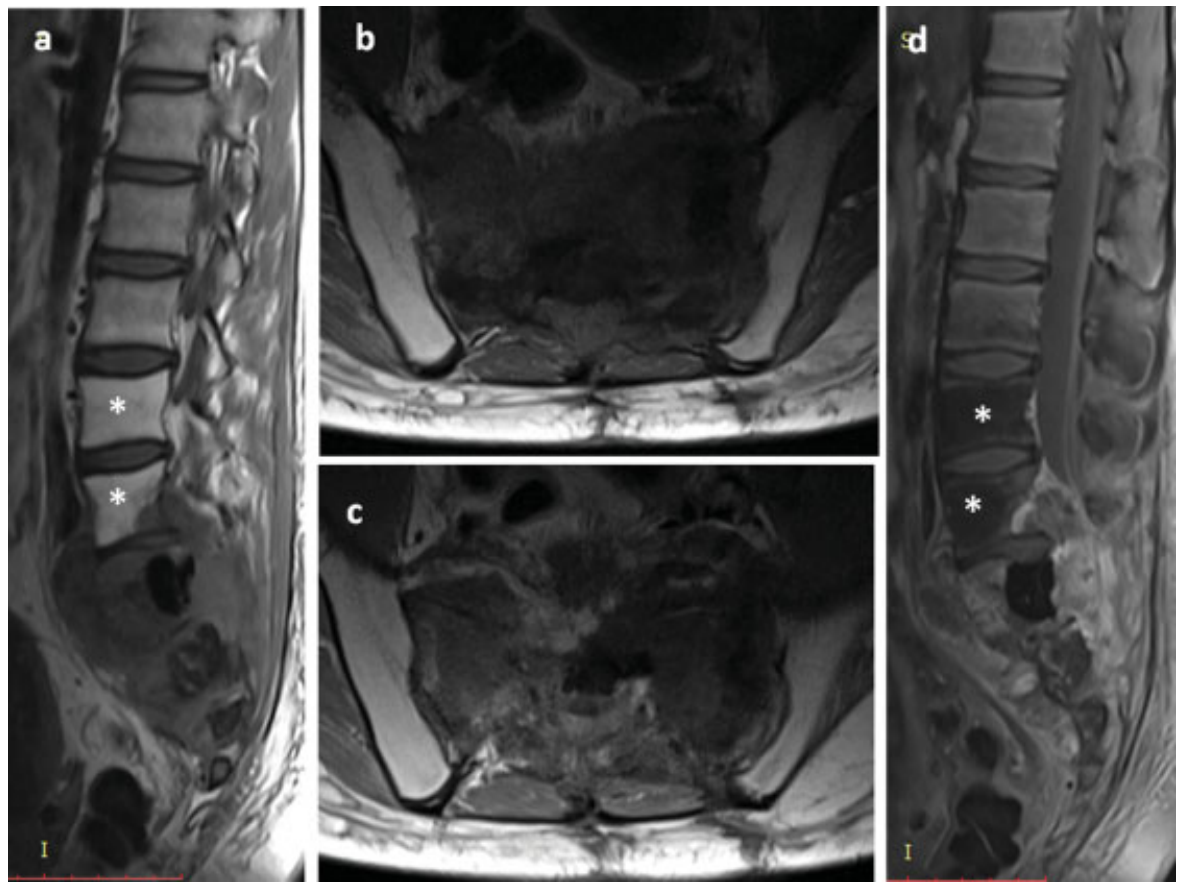

Fig. 20 Magnetic resonance (MR) imaging scan of the same patient 6 weeks after open biopsy and palliative radiation therapy. (a) Sagittal T1weighted, (b, c) axial T1-weighted, (d) sagittal postcontrast T1-weighted MR image with fat saturation. Destructive mass lesion of the sacrum invading the L5 vertebra and sacroiliac joints with accompanying presacral and epidural soft tissue component. Note the fatty bone marrow infiltration due to radiation therapy (white asterisks).

nonmineralized portion of the tumor displays high signal on T2-weighted sequences (- Figs. 20 and 21). In telangiectatic osteosarcoma, a soft tissue mass and fluid-fluid levels are typical. Osteosarcomas display heterogeneous contrast enhancement fallowing contrast administration.
As with Ewing sarcoma/primitive neuroectodermal tumor (PNET) lesions of the spine, complete surgical resection with spinal osteosarcomas is usually not possible. Death usually occurs within 1 year of diagnosis. The survival rates are lower in patients with sacral tumors. ${ }^{36}$
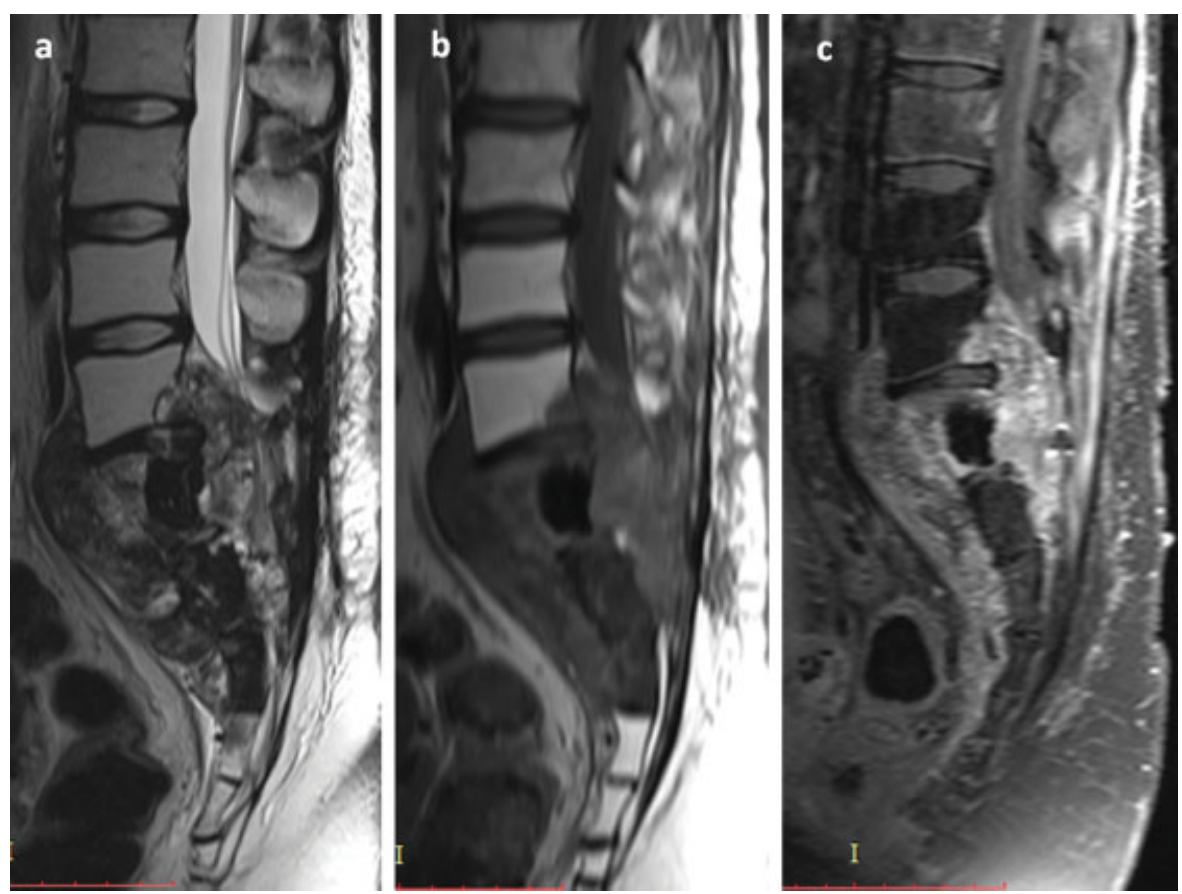

Fig. 21 Same patient following adjuvant chemotherapy with partial response. (a) Sagittal T2-weighted, (b) T1-weighted, (c) postcontrast T1weighted magnetic resonance images with fat saturation. 


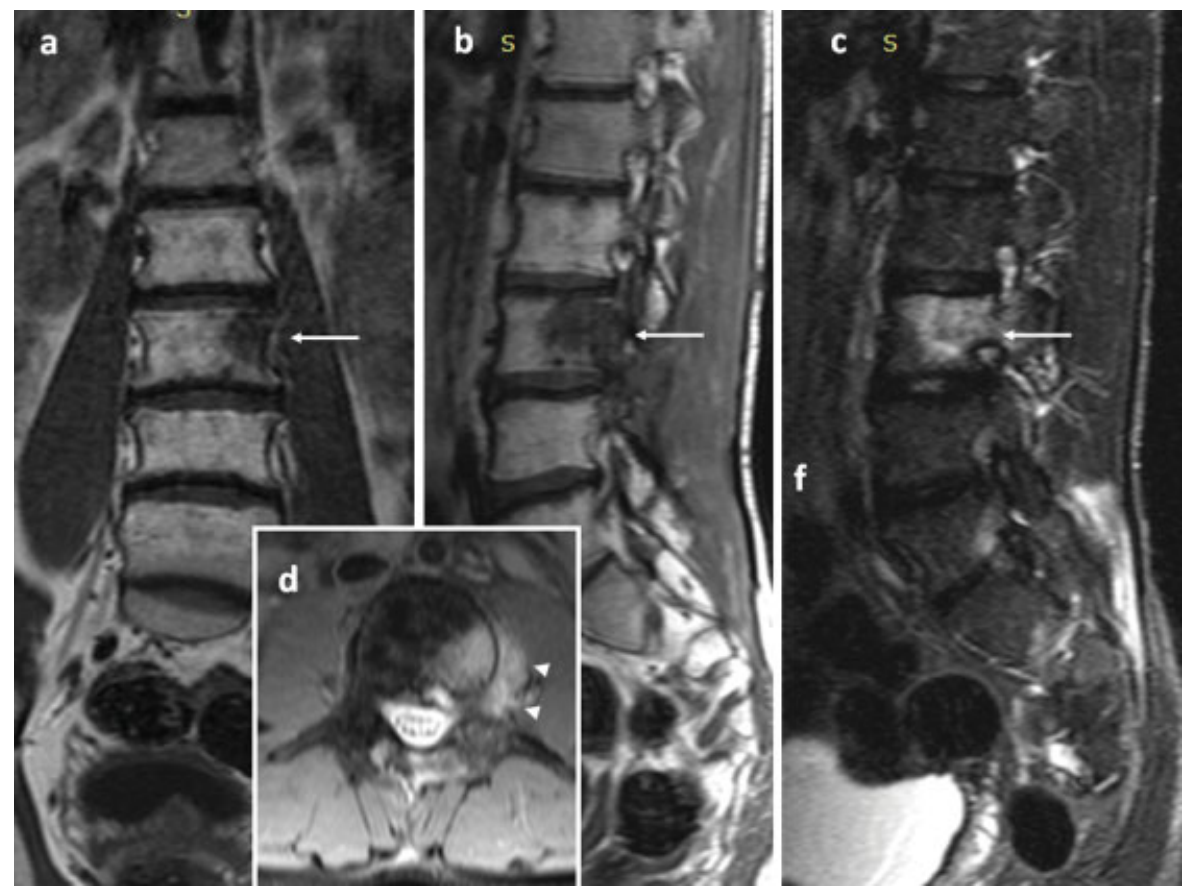

Fig. 22 A 21-year-old male patient with a lumbar Ewing tumor. (a) Coronal T1-weighted, (b) sagittal T1-weighted magnetic resonance images, (c) short tau inversion recovery image, (d) axial fast spin-echo proton density with fat saturation image shows a mass lesion at the right side of the L3 vertebral body (arrows) with a small soft tissue component infiltrating the left psoas muscle (arrowheads).

Ewing Sarcoma and Primitive Neuroectodermal Tumor Ewing sarcoma and PNET are indistinct entities with very similar pathologic, clinical, and radiologic characteristics. They are the most common nonlymphoproliferative primary malignant tumors of the spine in children and adolescents. There is mild male predilection. Lesions of the spine account for 3 to $10 \%$ of all primary sites of Ewing sarcoma/PNET. ${ }^{36,40}$ However, metastatic involvement of spine from other foci of
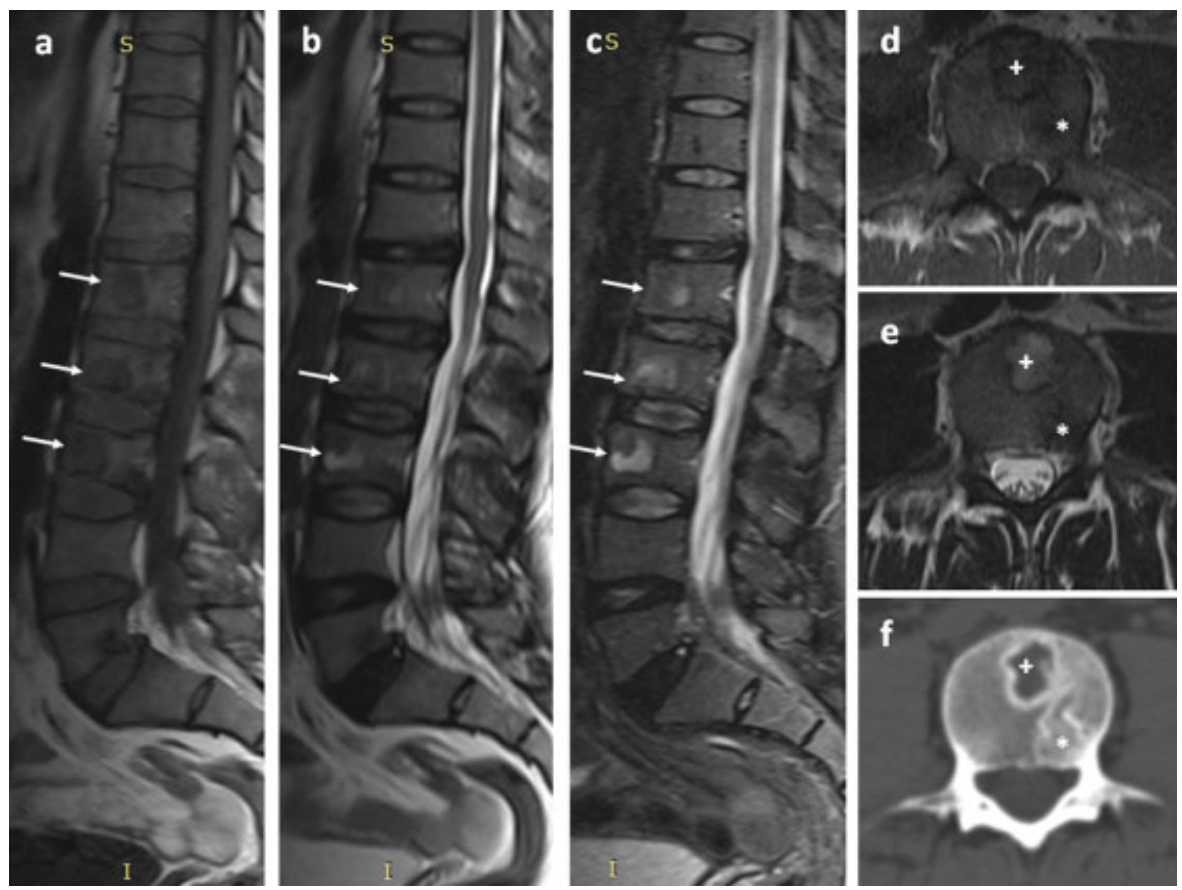

Fig. 23 A 39-year-old man with polyostotic fibrous dysplasia. (a) Sagittal T1-weighted, (b) sagittal T2-weighted, (c) sagittal short tau inversion recovery, (d) axial T1-weighted, (e) axial T2-weighted magnetic resonance images, (f) axial computed tomography (CT) scan demonstrating multiple lesions (arrows) at the bodies of L1, L2, L3, and L5 vertebrae displaying cystic (white plus sign) and sclerotic components, with typical ground-glass appearance on CT (white asterisks). 

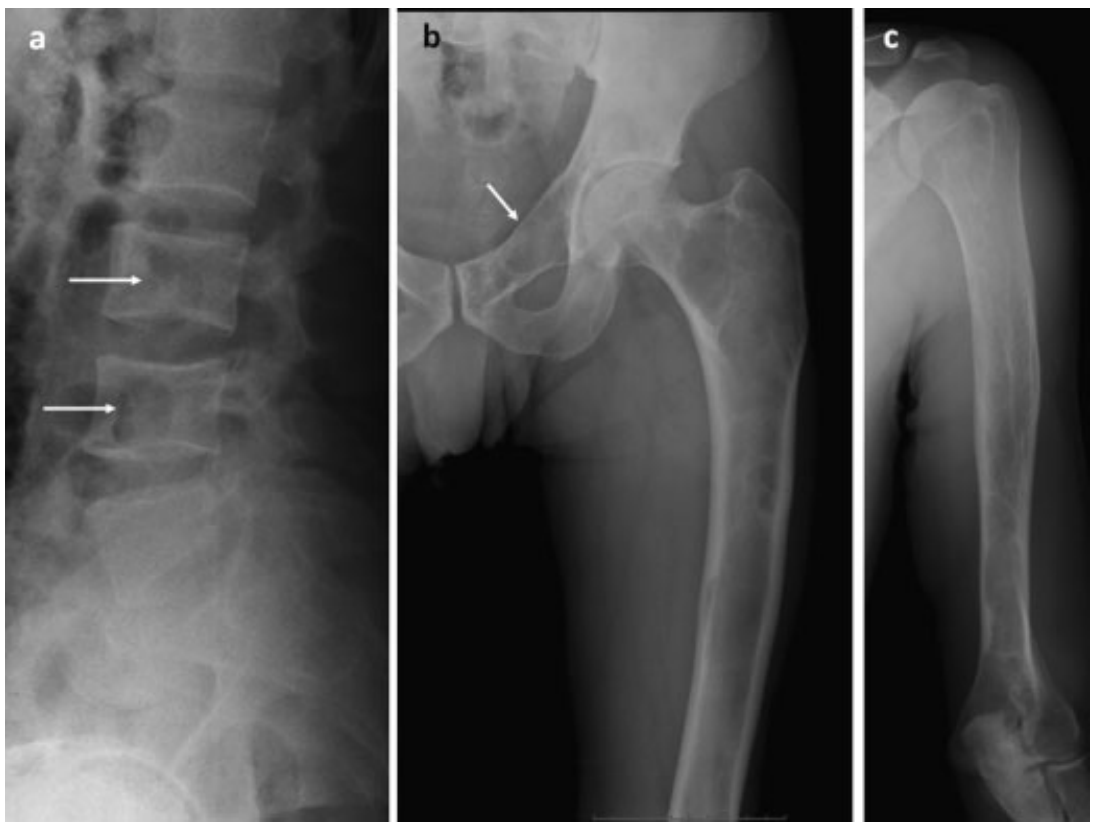

Fig. 24 The same patient. (a) Lateral lumbar, (b) anteroposterior (AP) left proximal femur, (c) AP left humerus X-rays showing the lytic lumbar (arrows) and multiple expansile deforming lesions of the pubic ramus (arrow), femur, and humerus.

primary Ewing sarcoma/PNET is much more common than primary lesions. The most common location for primary lesions is the sacrococcygeal region, followed by the lumbar and the thoracic spine. Cervical spine involvement is rare. ${ }^{40}$

Histologically, they are composed of small round blue cells with large irregular sheets of cells divided by septa, scant cytoplasm, and abundant collagen. Spinal lesions frequently display areas of necrosis. ${ }^{41}$ These tumors have various radiologic patterns with most demonstrating aggressive bone destruction, lysis, and large paraspinal soft tissue components. Vertebra plana has also been reported. MR imaging shows intermediate signal intensity on T1-weighted and
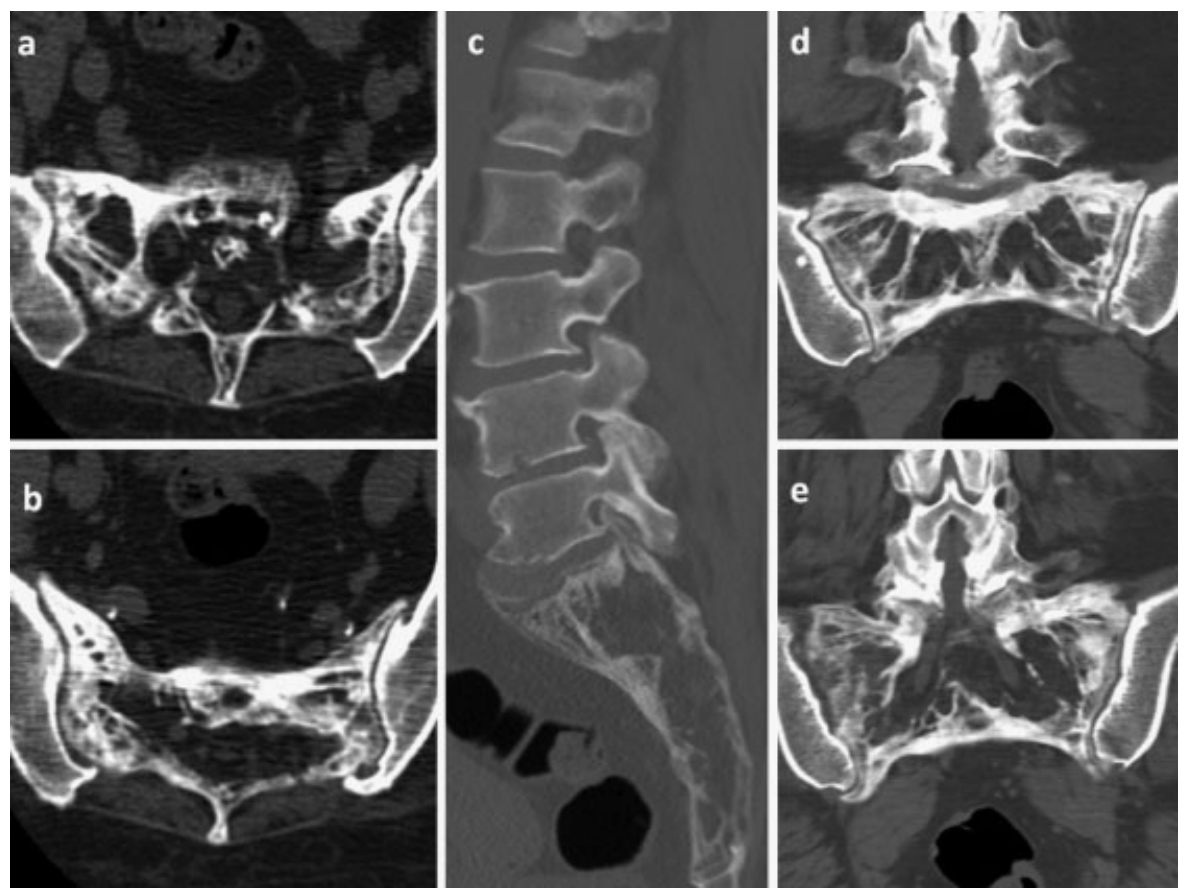

Fig. 25 Computed tomography scan of Paget disease of the sacrum in a 57-year-old female patient. (a, b) Axial images, (c) sagittal, (d, e) coronal reconstructed images displaying marked cortical thickening and trabecular coarsening of sacrum with enlargement of the sacral spinal canal and neural foramina. 

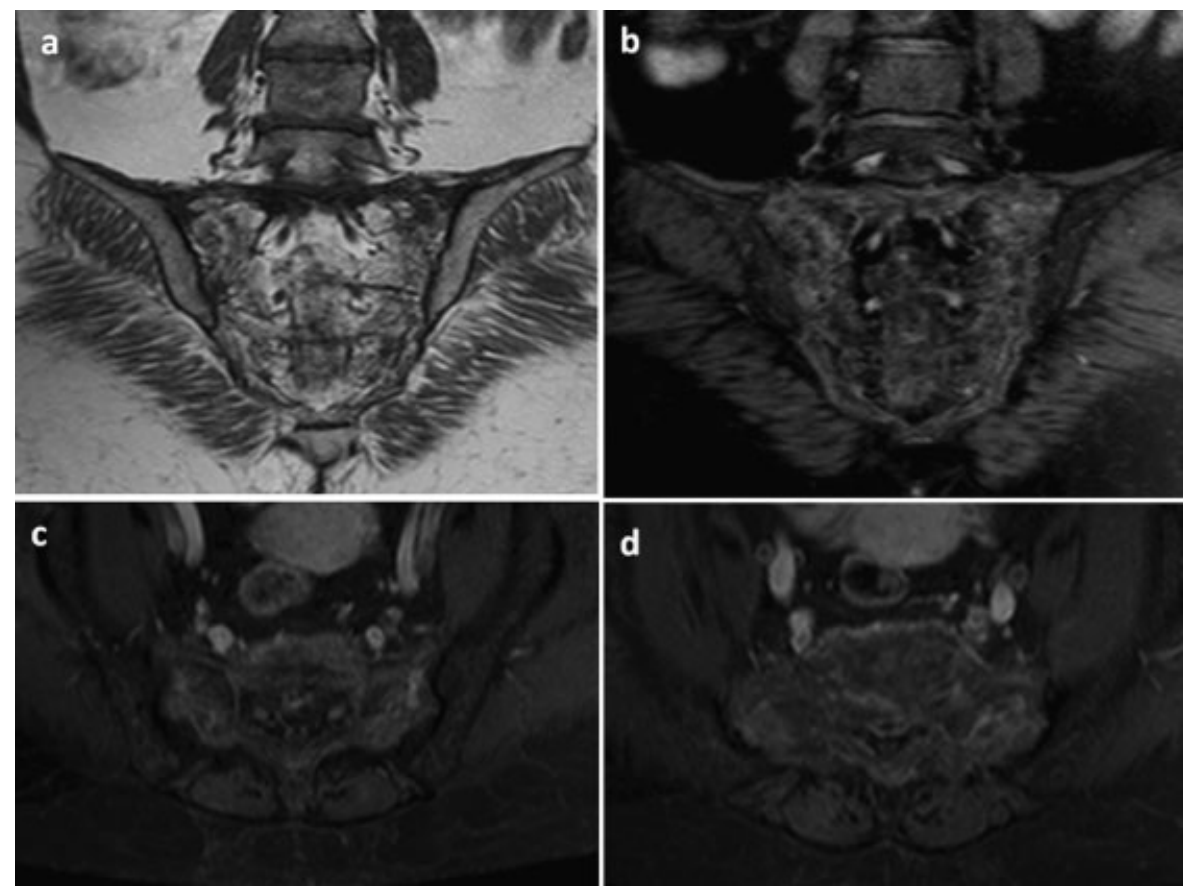

Fig. 26 Magnetic resonance (MR) imaging of the same patient with Paget disease of the sacrum. (a) T1-weighted paracoronal MR image displaying intermediate T1 signal of sacral bone, preservation of epidural fat planes. (b) T2-weighted paracoronal MR image displaying heterogeneous $\mathrm{T} 2$ high signal of sacrum. (c, d) Postcontrast axial T1-weighted MR images with fat saturation showing moderate enhancement of sacral bone.

intermediate to high signal intensity on T2-weighted MR images (-Fig. 22).

Similar to osteosarcomas of the spine, surgical resection is often not feasible because of the lesion location and large size of soft tissue components. Chemotherapy and radiation treatment are the mainstay of therapeutic options.

\section{Tumorlike Lesions}

Several developmental, inflammatory, metabolic, focal reactive, and posttraumatic entities may mimic both benign and malignant tumors of the spine. Although they do not represent true neoplasms, tumorlike lesions should be considered in the differential diagnosis of spine lesions. Paget disease and fibrous dysplasia are two tumorlike lesions that may also involve the spine as well as the appendicular skeleton. Fibrous dysplasia is often purely lytic but may have a typical groundglass appearance as the matrix calcifies. The MRI signal depends on the amount of calcification, ossification, and fibrous tissue, which present low signal, and cystic components with high $\mathrm{T} 2$ signal (-Figs. 23 and 24). Paget disease is a localized disorder of bone remodeling that typically begins with an excessive osteoclastic activity followed by a compensatory bone formation, leading to a coarsened and disorganized trabecular pattern (-Figs. 25 and 26 ).

\section{Conclusion}

Spinal tumors are frequently detected on imaging studies performed for various indications. We have reviewed some of the imaging features of spinal tumors in this article and summarize them in - Table 1. Multiple spinal lesions can be ascribed to known metastatic disease or lymphoproliferative disease. However, in solitary lesions, primary neoplasms of the spine should be considered. The radiologist should be aware of the characteristic imaging features of spinal lesions to tailor the diagnostic work-up. Although plain radiographs may be useful to characterize some spinal lesions, MR imaging is indispensable to determine the extension and the relationship with the spinal canal and nerve roots, and thus determine the plan of management.

\section{References}

1 Smith JK, Lury K, Castillo M. Imaging of spinal and spinal cord tumors. Semin Roentgenol 2006;41(4):274-293

2 Smith J, Wixon D, Watson RC. Giant-cell tumor of the sacrum. Clinical and radiologic features in 13 patients. J Can Assoc Radiol 1979;30(1):34-39

3 Murphey MD, Andrews CL, Flemming DJ, Temple HT, Smith WS, Smirniotopoulos JG. From the archives of the AFIP. Primary tumors of the spine: radiologic pathologic correlation. Radiographics 1996;16(5):1131-1158

4 Chai JW, Hong SH, Choi JY, et al. Radiologic diagnosis of osteoid osteoma: from simple to challenging findings. Radiographics 2010;30(3):737-749

5 Nogués P, Martí-Bonmatí L, Aparisi F, Saborido MC, Garci J, Dosdá R. MR imaging assessment of juxta cortical edema in osteoid osteoma in 28 patients. Eur Radiol 1998;8(2):236-238

6 Azouz EM, Kozlowski K, Marton D, Sprague P, Zerhouni A, Asselah F. Osteoid osteoma and osteoblastoma of the spine in children. Report of 22 cases with brief literature review. Pediatr Radiol $1986 ; 16(1): 25-31$ 
7 Swank SM, Barnes RA. Osteoid osteoma in a vertebral body. Case report. Spine 1987;12(6):602-605

8 Liu PT, Kujak JL, Roberts CC, de Chadarevian JP. The vascular groove sign: a new CT finding associated with osteoid osteomas. AJR Am J Roentgenol 2011;196(1):168-173

9 Davies M, Cassar-Pullicino VN, Davies AM, McCall IW, Tyrrell PN. The diagnostic accuracy of MR imaging in osteoid osteoma. Skeletal Radiol 2002;31(10):559-569

10 Assoun J, Richardi G, Railhac JJ, et al. Osteoid osteoma: MR imaging versus CT. Radiology 1994;191(1):217-223

11 Ilaslan H, Sundaram M. Advances in musculoskeletal tumor imaging. Orthop Clin North Am 2006;37(3):375-391, vii

12 Gangi A, Alizadeh H, Wong L, Buy X, Dietemann JL, Roy C. Osteoid osteoma: percutaneous laser ablation and follow-up in $114 \mathrm{pa}-$ tients. Radiology 2007;242(1):293-301

13 Gangi A, Basile A, Buy X, Alizadeh H, Sauer B, Bierry G. Radiofrequency and laser ablation of spinal lesions. Semin Ultrasound CT MR 2005;26(2):89-97

14 Kroon HM, Schurmans J. Osteoblastoma: clinical and radiologic findings in 98 new cases. Radiology 1990;175(3):783-790

15 McLeod RA, Dahlin DC, Beabout JW. The spectrum of osteoblastoma. AJR Am J Roentgenol 1976;126(2):321-325

16 Lucas DR, Unni KK, McLeod RA, O'Connor MI, Sim FH. Osteoblastoma: clinicopathologic study of 306 cases. Hum Pathol 1994; 25(2):117-134

17 Kransdorf MJ, Sweet DE. Aneurysmal bone cyst: concept, controversy, clinical presentation, and imaging. AJR Am J Roentgenol 1995;164(3):573-580

18 Beltran J, Simon DC, Levy M, Herman L, Weis L, Mueller CF. Aneurysmal bone cysts: MR imaging at $1.5 \mathrm{~T}$. Radiology 1986; 158(3):689-690

19 Vidal JA, Murphey MD. Primary tumors of the osseous spine. Magn Reson Imaging Clin N Am 2007;15(2):239-255, vii

20 Mankin HJ, Hornicek FJ, Ortiz-Cruz E, Villafuerte J, Gebhardt MC. Aneurysmal bone cyst: a review of 150 patients. J Clin Oncol 2005; 23(27):6756-6762

21 Bidwell JK, Young JW, Khalluff E. Giant cell tumor of the spine: computed tomography appearance and review of the literature. J Comput Tomogr 1987;11(3):307-311

22 Schwimer SR, Bassett LW, Mancuso AA, Mirra JM, Dawson EG. Giant cell tumor of the cervicothoracic spine. AJR Am J Roentgenol 1981;136(1):63-67

23 Chhaya S, White LM, Kandel R, Wunder JS, Ferguson P, Agur A. Transarticular invasion of bone tumours across the sacroiliac joint. Skeletal Radiol 2005;34(12):771-777

24 Kwon JW, Chung HW, Cho EY, et al. MRI findings of giant cell tumors of the spine. AJR Am J Roentgenol 2007;189(1):246-250
25 Giudicissi-Filho M, de Holanda CV, Borba LA, Rassi-Neto A, Ribeiro CA, de Oliveira JG. Cervical spinal cord compression due to an osteochondroma in hereditary multiple exostosis: case report and review of the literature. Surg Neurol 2006;66(Suppl 3):S7-S11

26 Ratliff J, Voorhies R. Osteochondroma of the C5 lamina with cord compression: case report and review of the literature. Spine 2000; 25(10):1293-1295

27 Ross JS, Masaryk TJ, Modic MT, Carter JR, Mapstone T, Dengel FH. Vertebral hemangiomas: MR imaging. Radiology 1987;165(1): 165-169

28 Choi JJ, Murphey MD. Angiomatous skeletal lesions. Semin Musculoskelet Radiol 2000;4(1):103-112

29 Enzinger FM, Weiss SW. Benign Tumors and Tumor Like Lesions of Blood Vessels in Soft Tissues Tumors. St. Louis, MO: Mosby-Year Book; 1995:579-526

30 Acosta FL Jr, Dowd CF, Chin C, Tihan T, Ames CP, Weinstein PR. Current treatment strategies and outcomes in the management of symptomatic vertebral hemangiomas. Neurosurgery 2006;58(2): 287-295; discussion 287-295

31 Kransdorf MJ, Smith SE. Lesions of unknown histogenesis: Langerhans cell histiocytosis and Ewing sarcoma. Semin Musculoskelet Radiol 2000;4(1):113-125

32 Brown CW, Jarvis JG, Letts M, Carpenter B. Treatment and outcome of vertebral Langerhans cell histiocytosis at the Children's Hospital of Eastern Ontario. Can J Surg 2005;48(3):230-236

33 Sung MS, Lee GK, Kang HS, et al. Sacrococcygeal chordoma: MR imaging in 30 patients. Skeletal Radiol 2005;34(2):87-94

34 Rosenthal DI, Scott JA, Mankin HJ, Wismer GL, Brady TJ. Sacrococcygeal chordoma: magnetic resonance imaging and computed tomography. AJR Am J Roentgenol 1985;145(1):143-147

35 de Bruïne FT, Kroon HM. Spinal chordoma: radiologic features in 14 cases. AJR Am J Roentgenol 1988;150(4):861-863

36 Flemming DJ, Murphey MD, Carmichael BB, Bernard SA. Primary tumors of the spine. Semin Musculoskelet Radiol 2000;4(3):299-320

37 Barwick KW, Huvos AG, Smith J. Primary osteogenic sarcoma of the vertebral column: a clinicopathologic correlation of ten patients. Cancer 1980;46(3):595-604

38 Ilaslan H, Sundaram M, Unni KK, et al. Primary vertebral osteosarcoma: imaging findings. Radiology 2004;230(3):697-702

39 Bloem JL, Kroon HM. Osseous lesions. Radiol Clin North Am 1993; 31(2):261-278

40 Ilaslan H, Sundaram M, Unni KK, Dekutoski MB. Primary Ewing's sarcoma of the vertebral column. Skeletal Radiol 2004;33(9): 506-513

41 Shirley SK, Gilula LA, Siegal GP, Foulkes MA, Kissane JM, Askin FB. Roentgenographic-pathologic correlation of diffuse sclerosis in Ewing sarcoma of bone. Skeletal Radiol 1984;12(2):69-78 